Florida International University

FIU Digital Commons

FIU Electronic Theses and Dissertations

University Graduate School

$10-20-2016$

\title{
Meaning Negotiated Through Independently- Written Summaries and Oral Academic Conversations: Enhancing Comprehension of Science Text by Ninth-Grade, English Learners
}

Edward C. Burke

Florida International University, eburk001@fiu.edu

DOI: 10.25148 /etd.FIDC001214

Follow this and additional works at: https://digitalcommons.fiu.edu/etd

Part of the Bilingual, Multilingual, and Multicultural Education Commons, Curriculum and Instruction Commons, Educational Methods Commons, and the Science and Mathematics Education Commons

\section{Recommended Citation}

Burke, Edward C., "Meaning Negotiated Through Independently-Written Summaries and Oral Academic Conversations: Enhancing Comprehension of Science Text by Ninth-Grade, English Learners" (2016). FIU Electronic Theses and Dissertations. 3008.

https://digitalcommons.fiu.edu/etd/3008

This work is brought to you for free and open access by the University Graduate School at FIU Digital Commons. It has been accepted for inclusion in FIU Electronic Theses and Dissertations by an authorized administrator of FIU Digital Commons. For more information, please contact dcc@fiu.edu. 


\section{FLORIDA INTERNATIONAL UNIVERSITY}

Miami, Florida

\section{MEANING NEGOTIATED THROUGH INDEPENDENTLY-WRITTEN \\ SUMMARIES AND ORAL ACADEMIC CONVERSATIONS: ENHANCING \\ COMPREHENSION OF SCIENCE TEXT BY NINTH-GRADE, ENGLISH \\ LEARNERS}

A dissertation submitted in partial fulfillment of

the requirements for the degree of

DOCTOR OF EDUCATION

in

CURRICULUM AND INSTRUCTION

by

Edward Charles Burke 
To: Dean Michael R. Heithaus

College of Arts, Sciences, and Education

This dissertation, written, Edward Charles Burke, and entitled Meaning Negotiated Through Independently-Written Summaries and Oral Academic Conversations:

Enhancing Comprehension of Science Text by Ninth-Grade, English Learners, having been approved in respect to style and intellectual content, is referred to you for judgment.

We have read this dissertation and recommend that it is approved.

Lynne D. Miller

George E. O'Brien

Leonard B. Bliss

Joyce C. Fine, Major Professor

Date of Defense: October 20, 2016

The dissertation of Edward Charles Burke is approved.

Dean Michael R. Heithaus

College of Arts, Sciences, and Education

Andrés G. Gil

Vice President for Research and Economic Development and Dean of the University Graduate School

Florida International University, 2016 
Copyright by Edward Charles Burke All rights reserved. 


\section{DEDICATION}

I dedicate this dissertation to my wife, Madeleine, for her endurance throughout

the entire doctoral process. This dedication is also extended to my mother, father, and grandmother who instructed me in the value of education. 


\section{ACKNOWLEDGMENTS}

I want to thank God through Whom all things are possible. During the many days of frustration and fatigue, He empowered me to endure.

Needless to say, I want to thank my chair, Dr. Joyce C. Fine, who found a small reference to a Belgian study from the year 2000 and worked to guide me into developing it into this investigation which encompassed numerous current topics in literary research in addition to drawing upon my decades of classroom experience. She is also responsible for developing in me an interest in conducting research, which previously did not exist.

I want to thank my other committee members as well. Dr. Lynne D. Miller provided many insights and aided in shaping this study. Dr. George E. O'Brien enthusiastically supported the investigation from the moment I shared the idea with him. Further, he brought into it a dimension related to science education and sociocultural factors of which I was unaware. Without the help of Dr. Leonard B. Bliss, I would not have found evidence of the beneficial effect of the treatment. I am also thankful for the friendship he and I developed while working together.

I would also like to acknowledge the influence of the Hispanic adolescents of Hialeah, Florida. The motivation and struggles of my students over the decades have been a factor in the development of this treatment. 


\begin{abstract}
OF THE DISSERTATION
MEANING NEGOTIATED THROUGH INDEPENDENTLY-WRITTEN

SUMMARIES AND ORAL ACADEMIC CONVERSATIONS: ENHANCING

COMPREHENSION OF SCIENCE TEXT BY NINTH-GRADE, ENGLISH
\end{abstract}

LEARNERS

by

Edward Charles Burke

Florida International University, 2016

Miami, Florida

Professor Joyce C. Fine, Major Professor

English Learners experience challenges related to comprehension of science text particularly at the high school level. The language of science differs significantly from that of conversation and expository text. Students benefit from collaborative interpretation of readings. Additionally, there appears to be a need to train adolescents in the oral language skills requisite for academic discourse.

This study employed a sample of high school physical science students $(N=75)$ whose first language was Spanish and who were currently developing English language proficiency. It used quasi-experimental methodology with treatment and comparison groups, during the normal operations of the public school classroom. It tested the effect of training with a textbook summarization method and with an academic conversation strategy on the comprehension of state-adopted science textbook readings. Posttest scores of both groups were analyzed using an ANOVA. Posttest scores of treatment group 
members were analyzed in relation to prior science knowledge, reading level, gender, and level of English proficiency using a factorial ANOVA.

Findings suggest that the treatment had a positive impact on the achievement of students who had a low level of English language proficiency. In light of the at-risk nature of this population, given low socioeconomic status and that a high percentage of families are migrant workers, this in encouraging. The basic premise of the treatment appears promising. Evidence collected pertaining to its effect relative to students' general ESOL level, science background knowledge, literacy skills, and gender neither confirmed nor denied the viability of the strategy. The further significance of this study is that it adds to the body of research on strategies to support English Learners. 


\section{TABLE OF CONTENTS}

$\begin{array}{ll}\text { CHAPTER PAGE } & \text { PAT }\end{array}$

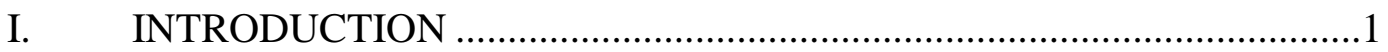

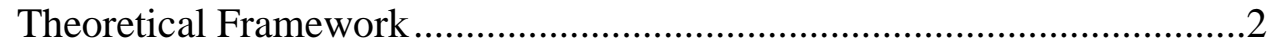

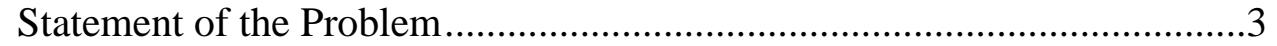

Purpose of the Study ..............................................................................6

Guiding Ideas ................................................................................ 9

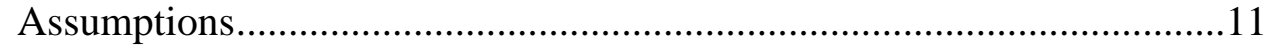

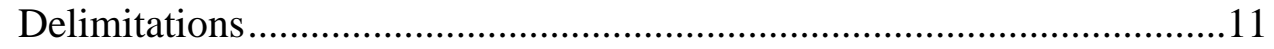

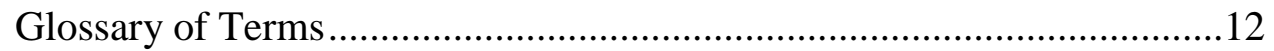

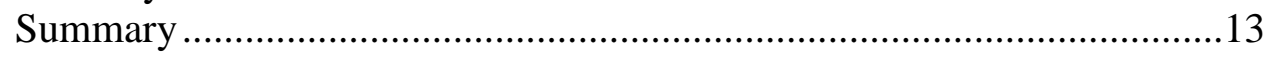

II. REVIEW OF LITERATURE ........................................................ 15

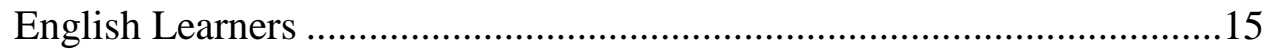

Adolescent Literacy ...........................................................................16

Gender and Academic Achievement .....................................................18

Disciplinary Literacy .........................................................................20

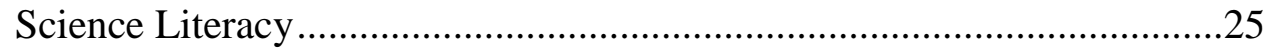

Collaborative Learning and Discussion ...............................................32

Oral Language and Discussion ..........................................................36

Adolescent ELs, Collaboration, and Disciplinary Literacy ......................38

Comprehension Strategy ......................................................................4 42

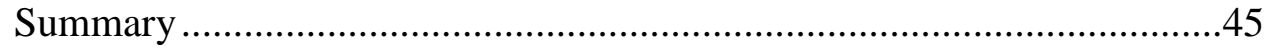

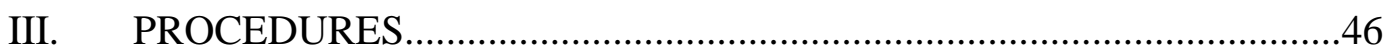

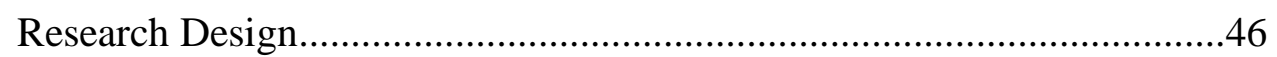

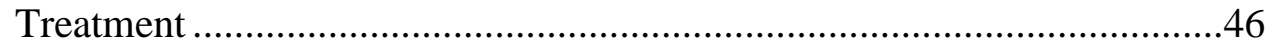

Van den Branden Study ........................................................................48

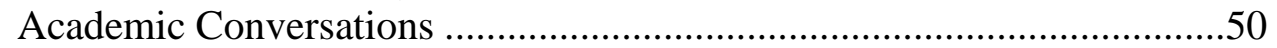

Literacy Circle ..................................................................................51

Derivation of Research Questions and Specific Research Hypotheses .....51

Research Questions and Specific Research Hypotheses ...........................52

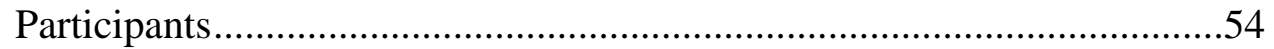

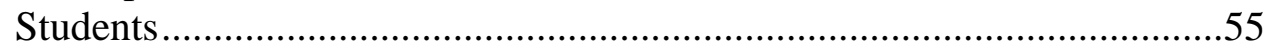

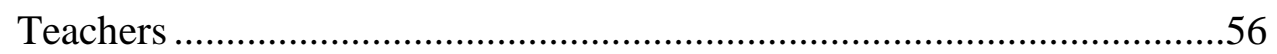

Classroom Teacher Training .............................................................56

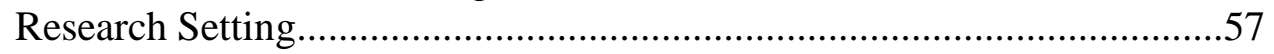

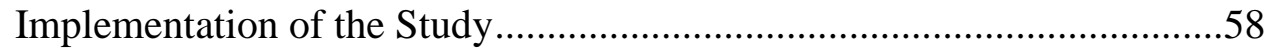

Teacher Interviews .....................................................................60

Instruments ................................................................................61

American Association for the Advancement of Science Examination ......62

The FCAT 2.0 Science....................................................................62

The Florida Standards Assessment English Language Arts ....................63 
The Comprehensive English Language Learning Assessment.................63

Additional Sources of Data Collection ......................................................64

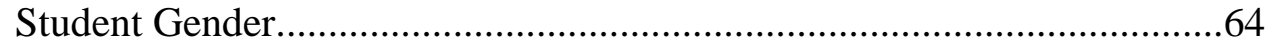

Observations of Treatment Groups .....................................................64

Teacher Perceptions of Treatment and Demographic Factors .................65

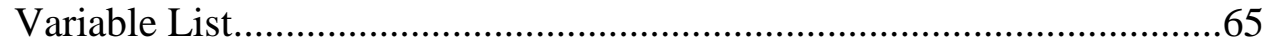

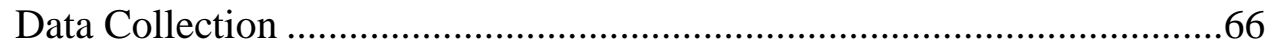

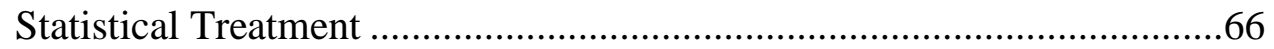

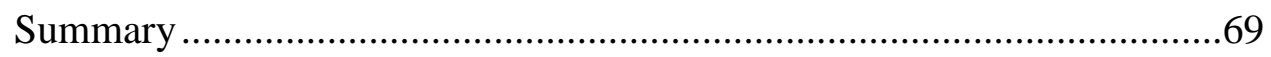

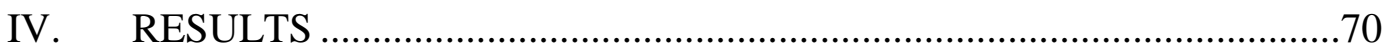

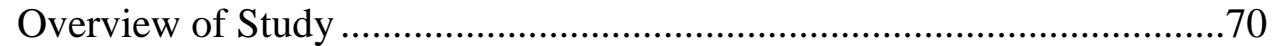

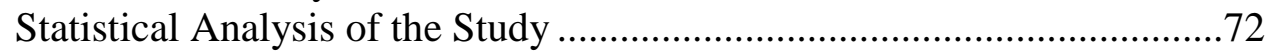

Results of Testing Research Hypotheses ................................................72

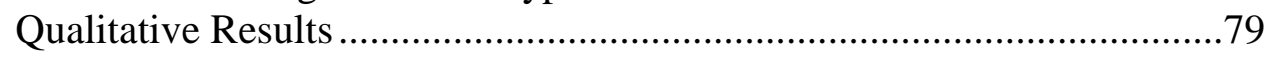

Observations of Treatment Groups .......................................................79

Teachers' Educational Background, Training, and Experience.................80

Teachers' Perceptions of the Treatment .............................................. 81

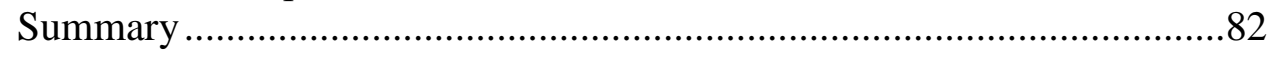

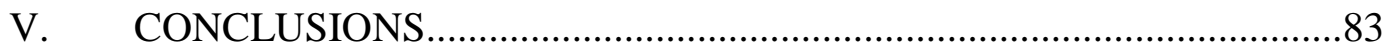

Restatement of Research Problem ....................................................83

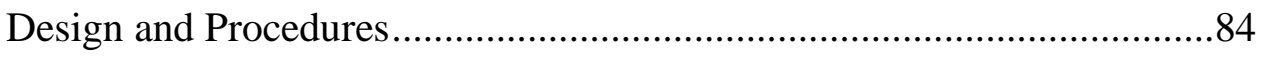

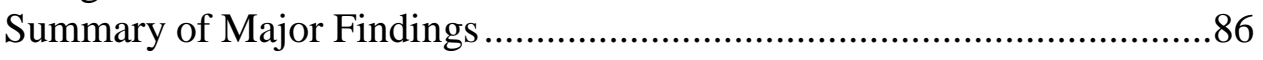

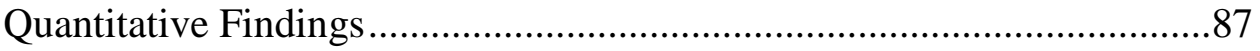

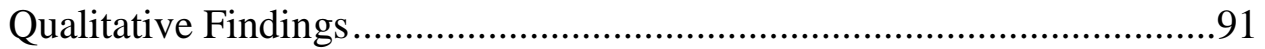

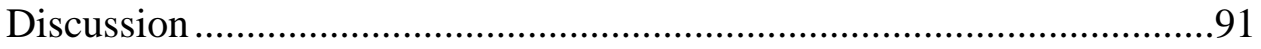

Suggested Future Research ........................................................96

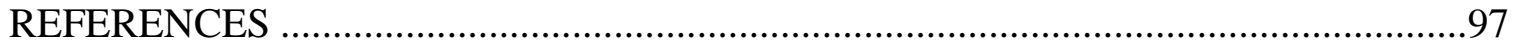

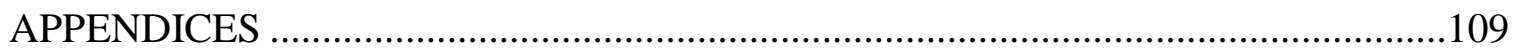

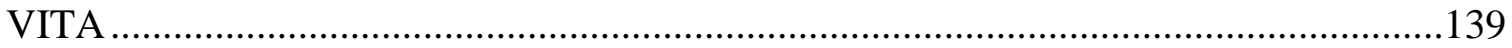




\section{CHAPTER I}

\section{INTRODUCTION}

Currently, across America there is a strong emphasis on STEM (science, technology, engineering, and mathematics) fields of study. The federal government's multibillion dollar Race to the Top award requires that states include a STEM provision in reform proposals (U.S. Department of Education, 2009).

United States (U.S.) President Barack Obama and former U.S. Secretary of Education Arne Duncan have stated that future economic prosperity, national security, public health, and the general quality of American life are dependent upon the nation's school children succeeding in STEM (U.S. Department of Education, 2009). Not since the Soviet Union's launch of Sputnik, over five decades ago, has there been the degree of national focus and fanfare centering on the importance of science instruction.

Diane Ravitch (educational policy analyst; research professor at the School of Culture, Education, and Human Development at New York University; and former Assistant Secretary of Education under George. H. W. Bush) stated that in recent years the country has seen numerous "authors describe in detail the alarming gaps in Americans' knowledge and understanding of political issues, scientific phenomenon, historical events, literary allusions, and almost everything else one needs to know to make sense of the world" (Ravitch, 2010, p. 223). In addition, competition from the rising economies of China and India is of great concern, as is the threat of a renewal of the Cold War with Russia and conflict in the Middle East. Fear surrounding the United 
States' ability to compete technologically and militarily has again made science education a priority.

\section{Theoretical Framework}

This study has been influenced in part by the sociocultural perspective: the Vygotskian view that human beings build conceptualizations through the interplay of their individual developmental stages, cultural orientations, and social contexts (Smagorinsky, 2009). Learning occurs through cooperative exchanges wherein modes of thinking are internalized. Vygotsky maintained that "the more complex the action demanded by the situation and the less direct its solution, the greater the importance played by speech [oral language] in the operation as a whole" (Vygotsky, 1978, p. 2526). This study looked into the impact of social groups and oral language on comprehension.

Further, the theoretical framework for this study is essentially rooted in constructivist theory, which establishes the rationale for its approach. This view holds that the student as an individual constructs knowledge which is mediated by the social group. Understanding of factual and conceptual information along with learning strategies is thereby developed (Berkeley, 2016). The student learns through interaction with the social environment as opposed to enculturation by the social environment (Scott \& Palincsar, 2013).

In this investigation, students placed in peer reading groups both observe and participate in the literary process. Such activity can result in learning that is sustained. Demonstration of the use of comprehension strategies, along with participation in the 
implementation of strategies used to discern the meaning of text, can lead to the internalization of these modes of learning.

This social interchange is vital in the process of knowledge acquisition. The strength of this collaborative approach may, in fact, be that meaning is negotiated through the combined effort of those participating in dialogic interpretation when confronted with the task of text comprehension, whether it is one with clarity or ambiguity or a combination thereof (Van den Branden, 2000). This study utilized small groups in which members explain interpretations and weigh peers' understanding of science text so as to develop comprehension ability and enhance understanding of textbook material.

\section{Statement of the Problem}

The White House, the U.S. Congress, state and local governments, and voters are inquiring as to possible means by which to increase the effectiveness of public education and thereby our students' academic development including their body of scientific knowledge. In response, the Florida Department of Education (FDOE) has implemented its high-stakes Biology End of Course (EOC) Assessment. This EOC impacts student grades, teacher evaluations, and school grades (FDOE Biology, 2013; FDOE EOC, 2013). EOCs in physics, chemistry, and physical science were piloted for the first time during the 2014-2015 school year and again during the 2015-2016 school year. Countywide implementation has been planned for spring of 2017 (Miami-Dade County Public Schools, 2014). Further, Miami-Dade County Public Schools (MDCPS) has already instituted district-developed, countywide interim assessments in these courses (MDCPS, 2014). 
Of the $10^{\text {th }}$ grade MDCPS students sitting for the 2014 biology EOC, 53\% passed (FDOE Results, 2015). Consequently, it is essential that districts and schools devise a means for improving learning in the science classroom and, thereby, test scores. High school science curricula require students to grasp numerous abstract concepts. Yet, students tend to come to the classroom with little background knowledge or relevant life experience in the sciences (Campbell \& Campbell, 2009). Teachers, endeavoring to cover benchmarks related to district and state assessment content, therefore, utilize as one of many tools, textbooks that are correlated to these standards. Hence there is a need to enhance comprehension skills relative to science text that can be effective regardless of the degree of students' body of prior knowledge.

Reading scores of American students, particularly those of adolescents, in comparison with those of other countries have been an issue for decades (National Center for Educational Statistics, 2010). Data from PISA (Program for International Student Assessment), a study by the OECD (Office of Economic Cooperation and Development) in 2009 (National Center for Educational Statistics, 2010), indicated a strong correlation between literacy skills of 15-year old students and their performance on science and mathematics assessments. Scores for the United States and 73 other nations were included. Only $30 \%$ of U.S. students had scores at the fourth level of reading proficiency, which indicates the ability to critically evaluate readings. Concerning science literacy, $29 \%$ had level 4 scores, which indicates the ability to select and integrate explanations from various fields of science and connect these to real world events. The predicament is exacerbated by the lack of training in literacy pedagogy of most content area teachers 
(Vacca \& Vacca, 2008). Methods are required whereby core area teachers can develop disciplinary reading skills in their classrooms.

The mandating of high-stakes standardized assessments, including recently implemented secondary school science assessments, by state departments of education (Miami-Dade County Public Schools, 2014; FDOE Biology, 2013; FDOE EOC, 2013) along with the high U.S. dropout rate (Bridgeland, Dilulio, \& Morison, 2006) are pressing factors. Means to increase student success in science need to be created. Enhancing comprehension of science text may be key.

A major factor impacting the development of science literacy in the U.S. is the pronounced increase in the English Learner (EL) population in recent years. Continued immigration has made for a situation in which the success of students who are English language learners is essential. According to the U.S. Census Bureau (2012), the Hispanic population, which includes a significant number of ELs, in the United States has risen from 9.1 million in 1970 to 52.0 million in 2011. It is projected to reach 66.4 million by 2020. The projected figure for 2050 is 132.8 million. This amounts to $16.7 \%$ of the nation's population as of 2011 and $30.2 \%$ by 2050 . Currently, $76.4 \%$ of U.S. residents under the age of 18 are Hispanic. The Southwestern United States and South Florida have the greatest Hispanic populations in the country. In 2009, the total population of MiamiDade County was estimated to be $2,531,769$. Of this, $1,582,355$ were Hispanic which is roughly $62.5 \%$.

It is evident that the need exists for the development of effective educational strategies geared toward increasing ELs' ability to comprehend science text and to achieve passing scores on state examinations. Students who are English learners (ELs) 
generally have difficulty related to literacy in English (August, McCardle, \& Shanahan, 2014). The challenge faced in content area subjects such as science is greater due to the demands of reading disciplinary text. Understanding of science vocabulary is a requisite for comprehension of science text.

This study was initiated to explore a strategy to support the development of comprehension of science text. It is in response to the expanding body of research focusing on this issue as it relates to adolescents and diverse students, ELs in particular (Conley, 2009; Fang, 2006; Hofstein, Navon, Kipnis, \& Mamlok-Naaman, 2004; Maloch, 2005; Tobin, 2005). Additionally, the study was in response to the recently created State of Florida End of Course science examinations, standardized assessments which may impact student grades, school grades, and teacher evaluations. In order to acquire the requisite subject area knowledge as well as to earn credit in high school science courses and to graduate, ELs must have the ability to learn grade-level science textbook content and to participate in conversations to build upon prior knowledge while concurrently developing content knowledge (Bunch. Kibler, \& Pimentel, 2012).

\section{Purpose of the Study}

This study sought to examine an intervention aimed at improving performance of ELs in science irrespective of level of English language proficiency, prior science knowledge, reading skills, and gender. It investigated the relationship between meaning negotiated through independent written summarization in conjunction with collaborative discussion, in student-conducted small groups, and the comprehension of a state adopted physical science textbook by ninth-grade ELs at various levels of English language 
proficiency. In this study, students classified as ELs were Hispanics whose first language is Spanish (Raphael \& Au, 2005). Physical science was selected in that it is a foundational course. Facts and concepts taught are drawn upon in other high school and university science classes including biology, chemistry, biochemistry, marine biology, anatomy and physiology, physics, astronomy, meteorology, geology, oceanography, and environmental science. Without a conceptual understanding of physical science, in that the field addresses the behavior of matter and energy including atomic theory and the electromagnetic spectrum, students will not be able to grasp the concepts presented in the other areas of science. The result can be that learning of science is reduced to rote memorization.

The study was conducted during general education high school science classes. The relationship between independently composed summaries of science textbook readings followed by student-conducted small group discussion thereof and scores on an American Association for the Advancement of Science (AAAS) Physical Science comprehensive examination (AAAS, 2015) as compared to the scores of comparison group students who did not participate in the summarization and discussion process were analyzed. The study sought to determine whether engaging in small group discussion along with both individually and collectively written summarizations of text meaning impacts comprehension ability of science students who are English learners regardless of reading levels, prior science knowledge, and Comprehensive English Language Learning Assessment (CELLA) score levels, and whether gender plays a role in the effect of discussion of text on assessment scores. 
An observation of the teachers' treatment groups occurred during the investigation for fidelity of implementation (see Appendix A). At the conclusion of the study, interviews were conducted related to teachers' perceptions of the treatment (see Appendix B). Interview questions pertained to viability of the treatment and suggestions for improvement. Teacher demographics such as educational background, training, and experience were recorded.

In the intervention, students silently read chapter material and individually composed summaries of passages read, which were handwritten in composition books. They applied the discourse moves for oral academic conversations of Zwiers and Crawford (2011) in a written form to organize thoughts on paper (see Appendix C). The authors had developed the strategy for the purpose of guiding students' oral discourse in small groups (see Appendix D). However, this investigation extended its original use by also applying the method for the purpose of guiding students' written summarization of text passages prior to their oral exchanges. Academic conversations are purposeful, sustained conversations on a subject area topic involving speaking, listening, and responding to partners. The strategy can develop core skills employed in academic conversations including elaboration and clarification, the support of ideas with evidence, extension or challenging of others' thoughts, synthesis of conversation points, and paraphrasing (Zwiers \& Crawford, 2011). Discourse moves are phrases designed to focus and direct student analytical thought and communication. Examples include:

I think it means. An illustration of this could be. Yet I wonder. In other words. The evidence seems to suggest. What makes you think that? What is a real world 
example? What might be some other points of view? What do we know so far? What can we agree on? (Zwiers \& Crawford, 2011, p. 73)

Following summarization of text, in small discussion groups, students utilized the conventional oral form of the strategy to guide discussion, in line with the original intent of Zwiers and Crawford, and then individually revised their summaries for accuracy of content.

The implementation of the discourse moves strategy fulfills requirements of six of the Common Core State Standards (2013) related to language arts and science. In addition, it is in line with the six corresponding Next Generation Science Standards (National Science Teachers' Association, 2015). (See Appendix E).

The reasons for testing the viability of this treatment were many. It grew out of literacy research related to general literacy; disciplinary areas, science in particular; collaborative learning; adolescents; and English learners. It requires little teacher training in the development of reading skills and hence is of value in content area classes. Its use of the independent, problem-solving small group is akin to the science class lab team.

\section{Guiding Ideas}

The study investigated the impact of summarization of text and academic conversations on comprehension in general and as relates specifically to English language proficiency, prior science knowledge, reading level, and gender. Several research questions were generated. 
Six ideas guided the study:

1. The first pertained to the physical science achievement of EL students, receiving standards-based instruction (that is, instruction based on the Next Generation Science Standards [NGSS] advocated by the National Science Teachers' Association [NSTA, 2015] and the Florida Department of Education [FDOE, Bureau, 2014]) following participation in either classes incorporating discussionbased small groups or in classes that did not employ discussion-based small groups.

2. The second addressed whether there is an interaction between the method of instruction and students' prior science knowledge in determining physical science achievement.

3. The third centered on whether there is an interaction between the method of instruction and students' reading levels in determining physical science achievement.

4. The fourth addressed whether there is an interaction between the method of instruction and students' ESOL levels in determining physical science achievement.

5. The fifth centered on whether there is an interaction between the method of instruction and student gender in determining physical science achievement.

6. The sixth related to teacher perceptions concerning the treatment. 


\section{Assumptions}

In this study, the researcher made the following assumptions:

- The subjects are a representative sample of Spanish-speaking English Learners in ninth-grade high school science classes in the Southeastern United States.

- The state adopted physical science textbook, published by CPO Science (Hsu et al., 2011), is comparable to books used by public schools nationally.

- The American Association for the Advancement of Science Physical Science comprehensive examination is comparable to state end of course assessments currently administered nationally.

- Deficiencies exist in the English language proficiency of students for whom standard American English is a second language that result in difficulties relative to disciplinary reading and standardized tests. This may not be evident through observation of student conversational English or through the English as a Second Language (ESOL) department Comprehensive English Language Learning Assessment (CELLA).

\section{Delimitations}

Several factors limited the scope of the investigation. These included:

- The ELs included were Hispanics whose first language is Spanish. Although the district in which the study was conducted has a significant 
number of students who are English Learners with other home languages, the predominant group is Spanish speakers.

- This study targeted low socioeconomic status students.

- High school classes were chosen in that state-mandated end of course assessments are administered at this level. In addition, the majority of atrisk students who drop out make the decision subsequent to entry into high school.

- Physical science was selected because the concepts learned in this course are foundational for all other branches of science.

\section{Glossary of Terms}

Academic conversations. Purposeful, sustained conversations on a subject area topic involving speaking, listening, and responding to partners (Zwiers \& Crawford, 2011). For the purpose of this study, it was the small group discussion of silently read science text.

Disciplinary text. Subject matter specific text (Shanahan \& Shanahan, 2012). For the purpose of this study, this included expository text in state and district approved textbooks used in content area classes including science, mathematics, and social studies.

Discourse moves. Core skills employed in academic conversations, including elaborate and clarify, support of ideas with evidence, extend or challenge other participants' thoughts, paraphrase, and synthesize conversation points (Zwiers \& Crawford, 2011). For the purpose of this study, this strategy was used by students for written organization of thoughts when summarizing silently read science text as well as for verbal interaction during small group discussion of readings. 
English learners. Students in American schools whose language spoken at home is not English and whose language proficiency is not considered fluent (Heineke, 2014). For the purpose of this study, this included Spanish speaking students born in the United States or elsewhere, currently or previously enrolled in classes for English language learners.

Meaning negotiated through collaboration. Students in small groups, through student-conducted discussion, collaboratively work to discern meaning of text (Van den Branden, 2000).

Science text. Content area text that is semantically dense in that comprehension is dependent upon a grasp of an ever increasing body of nomenclature thereby taxing prior knowledge (Alvermann, Gillis, \& Phelps, 2013). For the purpose of this study, this included expository text in state and district approved high school science textbooks currently used in a large urban public school district in the Southeastern United States and used by the subjects.

Standards-based instruction. Instruction which is aligned by educators with state and national standards, that is, the Next Generation Science Standards (National Science Teachers’'Association, 2003, 2015).

\section{Summary}

It is widely recognized that there exist political, social, and economic factors making it essential that American schools increase the body of science knowledge and literacy of students. Further, in light of the increasing Hispanic population, it is necessary to address the needs of English learners. The purpose of this study was to investigate the 
relationship between small group discussion by ELs of state adopted physical science textbook material and achievement on a comprehensive physical science assessment. Written academic conversations in conjunction with oral academic conversations were used to negotiate the meaning of text. Achievement was analyzed relative to prior science knowledge, reading level, ESOL level, and gender. 


\section{CHAPTER II}

\section{REVIEW OF LITERATURE}

This chapter reviews relevant research related to English learners, adolescent literacy, disciplinary learning, science literacy, collaborative learning, oral language, and comprehension strategies. This study was conducted to explore the impact of meaning negotiated through collaboration on the comprehension of science text by ninth-grade students with varying degrees of English language proficiency. Participants interacted in small student-led discussion groups. In such a context, individuals were provided the opportunity to discuss both academic vocabulary and content found in the textbook as

well as comprehension strategies employed and prior knowledge. Students were able to build upon one another's interpretations of the material by the composition of a group summary. The investigation sought to determine whether performance on physical science assessments could be improved regardless of reading level, prior knowledge of science, English language proficiency, and gender.

\section{English Learners}

In its report based on the evaluation of multiple investigations, the Alliance for Excellent Education (2003) confirmed what classroom teachers have long known, that students who are English learners experience greater challenges in disciplinary literacy acquisition than do native speakers. Raphael and Au (2005) pointed to the need for teachers to provide diverse students with literacy instruction focusing on comprehension strategies. They maintained that an achievement gap involving literacy exists between 
students of the mainstream and those who are diverse in terms of first language, ethnic background, social status, and economic level. The latter group is not being given the type of comprehension instruction necessary for academic content learning or for success

on state assessments. The result of the omission by teachers of comprehension skill instruction geared toward diverse students impedes their access to higher education and to careers that could impact them socioeconomically. This study tests a means through which such literacy skills may be developed in ELs to facilitate an increase in content area knowledge.

The National Assessment of Educational Progress (NAEP) stated that average reading scores of eighth-grade ELs showed no significant difference in achievement since 1998, but were lower than 2007. This relative maintenance of achievement occurred in spite of the national focus on reading and the proliferation of ESOL programs. It reported that $74 \%$ of the eighth-graders were below the basic level and only $3 \%$ were proficient. Among non-ELs, only $22 \%$ were below the basic level and $34 \%$ were either on or above the proficiency level (NAEP, 2009).

\section{Adolescent Literacy}

While ELs' scores appear bleak, data on students whose first language is English are not promising. The NAEP (2009) findings indicated that $66 \%$ are not proficient readers. The Alliance for Excellent Education (2003) called for more study in the area of adolescent comprehension in that middle schools and high schools report that students lack the reading skills to grasp textbook material. According to its report, $25 \%$ of secondary school students were deficient. In Standards for Middle and High School 
Literacy Coaches, the International Reading Association (2006) reported that students who fail to graduate from high school lack the literacy skills necessary to comprehend textbooks. This investigation involves adolescents' ability to read science text.

In the middle of the last decade, Bridgeland, Dilulio, and Morison (2006)

authored a report for the Bill and Melinda Gates Foundation. In it they stated that in the American public school system, the dropout rate was approximately $30 \%$, and was expected to increase by 2020 . This included a disproportionate number of students who are Hispanic and who are of low socioeconomic status. Of the overall U.S. population, $14.4 \%$ do not hold a high school diploma. Of the Hispanic population, the number is $37.8 \%$. Of the former group, $28.2 \%$ have earned a bachelor's degree. Of the latter, $13.0 \%$ are degreed. Comparing occupational status of the general population to the Hispanic segment, $35.9 \%$ are in management positions, compared with $19.0 \%$, and $18.0 \%$ are in the service sector, compared with $26.6 \%$. Generally, careers in management offer greater financial compensation and social advancement than careers in service areas. The National Center for Education Statistics (2012), of the U.S. Department of Education, reported that in 2010 the dropout rate for Hispanic students was 15\%. For Non-Hispanic Black students, it was $8 \%$ and for Non-Hispanic White students, it was 5\%. The National Dropout Prevention Center (2013), of Clemson University, claimed that the majority of prison inmates did not graduate from high school. Nationally the dropout rate is approximately $69 \%$ for individuals in municipal jails, 59\% in federal penitentiaries, and 75\% in state prisons. The Federal Bureau of Prisons (2013) stated that $34.9 \%$ of inmates are Hispanics. This equals 76,488 men and women. 
Reasons for leaving school given by students interviewed were numerous. Thirtyfive percent indicated they had failed multiple classes, $43 \%$ maintained they were not able to catch up on schoolwork, and $29 \%$ believed themselves incapable of meeting graduation requirements. The authors noted that the dropout rate had not significantly changed since the latter $20^{\text {th }}$ century even in light of the America's focus on educational reform. Students' lack of literacy skills, particularly the caliber demanded by state mandated, high stakes exams (that is, those required for high school graduation), is a likely factor contributing to this trend. This investigation aimed to develop a way of improving adolescent academic literacy.

Abedi (2002) reported findings that indicate a correlation between English language proficiency and achievement scores. In general, ELs' levels are lower than their non-EL peers in reading, mathematics, and the sciences. Further, the greater the language demands of a discipline, the greater the impact of language deficiency. Conley (2009) stated that improvement of adolescents' comprehension skills will necessitate determining the means by which the teacher can aid the student. It will also require a means by which students can aid themselves in both the understanding of and application of disciplinary comprehension strategies. In this study, a strategy was introduced for increasing standardized assessment scores of ELs in part by increasing disciplinary language acquisition.

\section{Gender and Academic Achievement}

English proficiency and adolescence are not lone factors impacting student success. Researchers report that gender may affect academic achievement, particularly 
concerning reading and the sciences. Lahelma (2014) stated that two discourses related to gender and education have been of critical concern for the past 30 years. The gender equality discourse involves the academic achievement of females. That involving males is referred to as the "boys discourse" (Lahelma, 2014, p. 171). Girls are held to have less proficiency in science than boys, but greater proficiency in language arts. Boys, on the other hand, are held to have less proficiency in literacy and greater difficulty in adjustment to the school environment.

This study investigated the influence of gender on comprehension of science text.

Based on an investigation of international achievement test data, Louis and Mistelle (2011) found that girls scored significantly lower than boys in physics, Earth science, and biology. An examination of historical documents dating back to the nineteenth century by Watts (2014) indicated that the fields of biology and medicine, as opposed to the physical sciences, were those with notable female participation. She attributes this to assumptions based on gender but also to the male power structure. Discouragement of female entry into STEM fields can decrease competition and may ensure positions of economic and political power for men. This circumstance appears to be pronounced in Silicon Valley where a disproportionately low percentage of the CEOs of the 100 top-ranked high-tech companies are women (Miller, 2010). Cunditt, Vescio, Loken, and Lo (2013), in research backed by the National Science Foundation, reported that women with stronger gender stereotype beliefs relative to science exhibited weaker aspirations to choose careers in science. Even in nations thought to advocate gender equality, female participation in STEM programs is significantly less than that of males 
(Sinnes \& Loken, 2014). In this investigation, comprehension of science concepts by girls was compared to that of boys.

The boys discourse, on the other hand, has to do with literacy skills, behavior, motivation, and attitude. Girls show greater achievement in the area of language and a significantly lower high school dropout rate (Hadjar, Krolak-Schwerdt, Priem, \& Glock, 2014). Cloer and Pearman (1993) found a substantial drop in male academic and recreational reading across the elementary school years. Hadjar et al. (2014) held that boys' socially influenced perceptions of gender identity may impact male performance. Recent research has suggested adjusting science curriculum to accommodate presumed differences in girls' and boys' interests. However, rather than remedying the situation, this approach may act to reinforce gender stereotypes (Sinnes \& Loken, 2014). Lahelma (2014) maintained that despite governmental efforts intended to address the gender equality discourse for female students along with the mass media's popularization of the boys discourse, no real change has been evident. Both the issue of achievement of girls in the sciences and the issue of the reading skills of boys require solutions. There seems to exist in the classroom a twofold need. This study addressed both issues.

\section{Disciplinary Literacy}

Content literacy has been defined by Vacca and Vacca $(2008$, p. 10) as "the ability to use reading, writing, talking, listening, and viewing to learn subject matter in a given discipline." Numerous factors impact student performance in the disciplines. These include background knowledge, discipline-specific language, conceptual challenges, assumptions of textbook manufacturers relative to students' knowledge and ability, and 
teachers' perspectives on the utility of the textbook in regard to instruction (Vacca \& Vacca, 2008). The concept of disciplinary literacy extends this definition. Experts in the areas of science, mathematics, and social studies do not approach the texts of each respective discipline with identical comprehension strategies. Students need to be taught these different modes for each core subject area (Shanahan \& Shanahan, 2008).

For more than a decade, there has been an increasing emphasis on expository text due to the demands of the digital age. Technical texts require a particular type of analytical thinking and set of literacy skills (Smith, 2003). The International Reading Association (2006) stated that adolescent literacy problems may be due to problems related to progressing from elementary school storybooks to secondary school core area textbooks. The issue of increasing text complexity requires student preparation so that the challenge may be faced and success realized. In response to reading data from its 2009 report, a National Assessment of Educational Progress board member called for greater emphasis on the development of literacy skills at the secondary school level in core areas such as history and science (Dillon, 2010). The investigation aimed to address comprehension of science textbooks.

The Alliance for Excellent Education (Alliance, 2007), in its report, Literacy Instruction in the Content Areas: Getting to the Core of Middle and High School Improvement, noted that the nation invested significantly in elementary reading programs during the last decades of the twentieth century. This is evidenced by President George H. W. Bush, in 2002, signing into law the bill known as No Child Left Behind (NCLB). This legislation increased local school accountability for student performance and federal control of education via federal funding (Klein, 2015). The intent of NCLB's Reading 
First Initiative was to ensure that every elementary school student would possess adequate literacy skills. The program ties funding to the implementation of instructional strategies and the use of assessments which are supported by scientific research (U.S. Department of Education NCLB, 2016).

The Alliance (2007) report maintained that in addition to basic literacy skills, secondary school students are in need of higher level literacy skills so as to be able to grasp the meaning of disciplinary texts including those in science classes. The ability to function at the college level, in the workplace, and as citizens of a democracy hinges on the acquisition of such skills. The programs promoted by educational reformers across the nation are not adequate to meet this need. Recommendations were made concerning content area instructors: Teachers should be enlisted to determine the type of literacy skills required by a discipline and should receive training in the instruction of these skills. The report stated that content area classes make up the crux of what is high school and that appropriate literacy skills are crucial for success in disciplinary classes, hence to ensure students a quality education, it is critical that they are instructed in the requisite comprehension strategies. This study looked into a method which can be implemented by core teachers so as to improve adolescent understanding of disciplinary readings.

Concerns of this nature have contributed to the development of Common Core State Standards related to disciplinary literacy. The Florida Department of Education (2013) maintained that the Common Core Standards are the product of educators and education experts from across the nation. They are the result of an initiative by the Council of Chief State School Officers and the National Governors' Association. They were slightly modified and adopted by the Florida State Board of Education in 2010. 
There are 10 standards on science literacy for ninth and tenth-grade students (Common Core, 2013) which directly correlate to the Next Generation Science Standards (NGSS) advocated by the National Science Teachers' Association (NSTA Next, 2015) and are in line with the Florida Standards (FDOE, Bureau, 2014). The six specifically related to this study are:

CCSS.ELA-Literacy.RST.9-10.1: Cite specific textual evidence to support analysis of science and technical texts, attending to the precise details of explanations and descriptions.

CCSS.ELA-Literacy.RST.9-10.2: Determine the central ideas or conclusions of a text; trace the text's explanation or depictions of a complex process, phenomenon, or concept, provide an accurate summary of the text.

CCSS.ELA-Literacy.RST.9-10.4: Determine the meaning of symbols, key terms, and other domain-specific words and phrases as they are used in a specific scientific or technical context relevant to grades 9 and 10 texts and topics. CCSS.ELA-Literacy.RST.9-10.5: Analyze the structure of relationships among concepts in a text, including relationships among key terms.

CCSS.ELA-Literacy.RST.9-10.9: Compare and contrast findings presented in a text to those from other sources (including their own experiments), noting when the findings support or contradict previous explanations or accounts.

CCSS.ELA-Literacy.RST.9-10.10: By the end of grade 10, read and comprehend science/technical texts in the grades 9 and 10 text complexity band independently and proficiently. 
In response to these standards, the 2016-2017 Miami-Dade County Public Schools District Pacing Guide for Physical Science (Miami-Dade County Public Schools Learning, 2016) has added a new benchmark:

Students will: Initiate and participate effectively in a range of collaborative discussions (one-on-one, in groups, and teacher-led) with diverse partners on grades 9 through 10 topics, texts, and issues, building on others' ideas and expressing their own clearly and persuasively. Come to discussions prepared, having read and researched material under study and explicitly draw on preparation by referring to evidence from text and other research on the topic or issue to stimulate a thoughtful, well-reasoned exchange of ideas. Work with peers to set rules for collegial discussions and decision-making (for example, informal consensus, taking votes on key issues, presentation of alternate views), clear goals and deadlines, and individual roles as needed. Propel discussions by posing and responding to questions that relate the current discussion to broader themes or larger ideas. Actively incorporate others into the discussion; and clarify, verify, or challenge ideas and conclusions. Respond thoughtfully to diverse perspectives, summarize points of agreement and disagreement, and when warranted, qualify or justify their own views and understanding and make new connections in light of evidence and reasoning presented.

In addition, the World-Class Instructional Design and Assessment Consortium (WIDA), comprised of 36 U. S. state departments of education and affiliated with the School of Education at the University of Wisconsin, has created English Language 
Development Standards (ELD) for students learning English in kindergarten through twelfth-grade (WIDA, 2013). The second through fifth levels of ELD Standard 1: Social and Instructional Language, Collaborative Discussion, relate to this study:

Level 2: Use statements to propel discussion.

Level 3: Paraphrase statements to propel discussion.

Level 4: Pose and respond to questions to propel discussion.

Level 5: Elaborate on responses to propel discussion.

\section{Science Literacy}

B. A. Brown (2011) proposed that student language and cultural identity bear an interrelationship which impacts learning in the science classroom. He stated that: If one appropriates a Vygotskian perspective on language and cognition that suggests that language is a primary mediator of cognition, then instruction that makes no affordances for language acquisition has the potential to increase the cognitive challenges associated with learning science. (p. 700)

He further claimed that language is a critical factor not only in attainment of knowledge but also in the construction of urban, minority students' ethnic identities and therefore it is imperative that teachers create strategies that facilitate the cultivation of discourse practices that support learning in science (B. A. Brown, 2005). This concept bares a relationship to Moje's Third Space (Moje et al., (2004) which pertains to the subculture in which English learners may reside which is neither American mainstream nor family ethnic culture but rather blend of some facets of both. This investigation examined the 
effect of peer discussion using student conversational language on science learning. Among its goals was student adeptness in the language of science.

Proponent of critical pedagogy, Paulo Freire, stated that "the educator with a democratic vision or posture cannot avoid in his [or her] teaching praxis insisting on the critical capacity, curiosity, and autonomy of the learner" (p. 33). That is, he proposes that the teacher with a concern for the wellbeing of the student, as both an individual and a member of this American democracy, incorporate into practice a means to foster the development of intellectual ability, interest, and independence in learning. In line with this end, Atwater (2010) advocated the development of multicultural science education. She stated that this requires educators to develop instructional techniques (including a focus on language and cooperative learning) that allow children and adolescents across socioeconomic, ethnic, cultural, and language groups to acquire a deep understanding of science. The goal is to provide the intellectual resources necessary for students to eventually effect social change locally, nationally, and worldwide. A call for a participatory democracy has been made by Mueller, Tippins, \& Bryan, 2010). They maintained there is a need for dialogue in science education so as to produce citizens who are able to collaborate in order to resolve issues related to eco-justice which may adversely impact subsequent generations. Gay (2009) claimed that multicultural education is in fact a "broker of democracy" (p. 25) for diverse students, particularly those who are struggling academically. This investigation looked into the impact of a democratic, communal dialogue among Hispanic students with varying English language proficiency and nationalities on the understanding of science. 
Barton (2009) reported findings that indicate when low socioeconomic status, minority high school students are given the opportunity for verbal expression in science classes, a partnership with teachers can be spawned which results in profound learning. Tobin (2006) reported that student argument concerning science, which encompasses disagreement and debate concerning the understanding of concepts and principles, can lead to academic success. He noted the need exists for student and teachers to produce a sense of classroom community and a joint responsibility for participation in learning. This study investigated the influence of argument in a classroom community on the grasping of scientific knowledge by ELs.

The intervention employed in this proposed study provided a vehicle whereby teachers could work to develop community in the classroom. It was a means through which students could incorporate the language and manner of communication of science into their personal-cultural discourse and thereby collectively discern meaning. For dialogue relative to science learning and sociopolitical change to occur, adolescents must grasp both the language and the modes of expression used by scientists. Conceptual understanding is dependent on student access to the language necessary for the task (B. A. Brown, 2011).

Fang (2006) held that the language of science education differs significantly from that of informal conversation and is, therefore, the cause of reading comprehension difficulties experienced by ELs. He pointed to the fact that the modern scientific system of classification stems in part from the work of Swedish scientist Carolus Linnaeus who utilized words from Latin. Strategies related to developing student awareness of Latin language roots of many of the technical terms of science can be beneficial. Of 
significance for this study, the ancient language bears a relationship to modern Spanish. For example, the modern Spanish word for "lung" is "pulmon" similar to the Latin word, "pulmonem." This study aimed to develop students' understanding of the language of science.

Secondary school English learners interviewed in a study identified a need for greater focus on the vocabulary of science (Lopez-Ferraro, 2008). Allen and Park (2011) agreed that the language of science and literacy challenges can adversely affect the learning of ELs. They noted that performance on everything from examinations to worksheets can suffer. Comprehension of science textbook material, lab manuals, science journals, news reports, and online information is dependent on comprehension of science vocabulary. This study measured the impact of discussion of the language of science on the EL literacy.

Kim and Linan-Thompson (2013) studied the use of expressive and receptive science vocabulary by ELs with learning disabilities. They claimed that the comprehension of terminology is critical for academic success and that the complexity of textbook sentences makes the use of context to infer meaning not viable. Instruction designed to aid ELs in this matter is indispensable. Technical language is needed by scientists to communicate knowledge with a high degree of accuracy (Campbell et al., 2007). Examples can be found in a textbook adopted by the State of Florida, Foundations of Physical Science (Hsu, Eddleman, Abel, \& Eldridge, 2011):

Current (I) is what carries power in a circuit. Current is measured in amperes (A). Voltage measures the difference in electrical potential energy between two points in a circuit. Voltage is measured in volts $(\mathrm{V})$. A difference in voltage causes 
current to flow. One volt is one watt per amp of current. Resistance (R) measures the ability to resist current. Resistance is measured in ohms. One amp of current flows if $1 \mathrm{~V}$ is applied across a resistance of one ohm. (p. 513) "Ampere," "voltage," "electrical potential energy," "volt," "watt," "amp," and "ohm" are technical terms specific to science while "current" and "resistance," although science nomenclature, have alternate meanings unrelated to the field. This can compound the difficulty of text for learners of English. Another instance of common words having multiple meanings is illustrated by the following sentence: "In a suspension, like muddy water, the particles are greater than 1,000 nanometers in diameter and can vary widely in size" (p. 443). In the school environment, the word "suspension" may be interpreted to mean a temporary expulsion from classes.

Numerous literary devices customary in science text can prove perplexing to English Learners. Lengthy nouns are extensive noun phrases within a sentence that in everyday conversation would be broken into several short sentences. For example: "The pressure stays the same in the larger cylinder, but area increased, resulting in a larger output force exerted by the piston" (p. 280). Complex sentences are those which have more than one dependent clause: "When flying in a parabola, the pilot maneuvers the plane so its path matches the path the passengers would follow if they were launched at an angle into the air at the speed of the plane" (p. 130). Nominalization involves transforming an adjective or verb into a noun. The term dissolution reaction is an example. It "occurs when an ionic compound (such as ammonium nitrate) dissolves in water to make an ionic solution" (p. 413). This study examined the way in which 
discussion of meaning of science text language can aid in the long-term interpretation of such by ELs.

Memorization of science vocabulary, however, is not a viable solution. Acquiring technical vocabulary should not be an activity separate from student acquisition of scientific concepts (Vacca \& Vacca, 2008). Schleppegrell (2006) identified other difficulties that the language of science and, therefore, science textbooks create. Informational texts have a high degree of density and nomenclature can be abstractions that comprise concepts as opposed to simple vocabulary words. "Students have to come to know their meanings well enough that they can use terms effectively in their speaking and writing" (p. 59). Several research reports have addressed these issues. The RAND Report on Reading Comprehension (RAND, 2002) and The Report of the National Reading Panel (National Reading Panel, 2000) have offered insights. Notably, that there is a strong relationship between comprehension by ELs and their knowledge of vocabulary and that student collaboration in the learning process can enhance comprehension as well as motivation. This investigation assessed this relationship.

Fang (2006) maintained that students' prior experiences and everyday language make for a pathway to the development of new vocabulary and the generation of knowledge. One he suggested was paraphrasing, the translation from the language of school science to students' everyday language. Another is sentence stripping, distilling complex sentences into their component parts. This involves student analysis of textbook sentences (Fang, 2006). This investigation considered collaborative student analysis of text utilizing student conversational language and its influence on comprehension. 
In fact, all of these suggested techniques are found in the study. Restatement of text vocabulary, summarization of text passages, and discussion of text meaning are in line with these recommendations. Corder (2007) cited three factors requiring public schools to develop and implement such a mode of differentiated instruction (DI) to facilitate the acquisition of science literacy skills by ELs: Federal law including the 2001 No Child Left Behind Act, the 1974 Educational Amendments Act Title II section known as the Equal Educational Opportunity Act, and the 1974 Congressional Amendment to the Bilingual Education Act of 1968, have long established a federal mandate. The ruling of the U.S. Supreme Court in the 1974 case, Lau vs. Nichols, required that adequate instruction be provided English learners by stating that failure to do so is in violation of the Civil Rights Act of 1964 (U.S. Department of Education, 2015). This undergirds the legislature's intent by declaring that ELs have a right to DI. There exists an ethical imperative to provide such equal opportunity to learners of English. The intervention implemented in this study contributed to the realization of this goal.

Gagnon and Abell (2009) agreed that a major challenge for English learners is the language of science. Often students cannot identify the first language equivalent of a science term and nomenclature used in textbook definitions may likewise be unfamiliar. To comprehend text, lectures, tests questions, and lab procedures, there is a need to participate in discourse aimed at the negotiation of meaning. Larson (2011) held that the use of the vocabulary of science by high school students in social groups expedites the grasping of concepts. This can be accomplished by small group discussion in the science classroom. Lee, Quinn, and Valdes (2013) concurred. They proposed that EL success in the science classroom requires the ability to use the language of science to compose 
explanations, develop arguments, and access and convey information. They indicated that discourse is one means of achieving these goals. This investigation incorporates all of these suggestions.

The American Association for the Advancement of Science (2013) is an international organization founded in the U.S. in the $19^{\text {th }}$ Century. Its mission pertains to the advancement of innovation in the field of science and among its goals is the furtherance of science education (AAAS History, 2016). As part of Project 2061, it published a statement on requisite student science skills, Benchmarks for Science Literacy: A Tool for Curriculum Reform. In the section on habits of mind and communication skills, it recommended participation in group discussions of science involving restatement and summarization of others' thoughts. The AAAS also called for students in discourse to be trained to request peer elaboration on and clarification of perspectives and to state alternative beliefs. The method of this study involves discourse related to text interpretation and summarization techniques.

\section{Collaborative Learning and Discussion}

Five decades ago, literacy icon A. Sterl Artley (1968) commented on the issue of disciplinary literacy. He maintained that the responsibility for instruction in comprehension strategies necessary in content area classes was that of the subject area teacher. Such teaching should be incorporated into the development of lessons (Alliance, 2003). However, Roberts, Takahashi, Park, and Stodden (2012, p. 41) noted that, "Content area teachers are often not equipped with effective strategies for teaching reading, even though their subjects may require students to read expository text and 
answer inferential questions." This study sought to employ an intervention that may be utilized by content area teachers.

In that success in all disciplines requires proficiency in reading, researchers and instructors involved in the field of adolescent literacy must seek the incorporation of literacy skill instruction in content area classes (Alliance, 2007). A research panel organized by the Alliance for Excellent Education published a report which outlined 15 critical research-based literacy practices geared toward the enhancement of adolescent literacy skills. Nine of these dealt with instructional strategies. Among those was a recommendation calling for implementation of collaborative small groups or paired student partners as a means of improving comprehension of disciplinary text (Biancarosa, 2005). The Alliance (2007) also noted that the development of literacy skills is not a solo pursuit. Individuals learn through interaction with those who possess a higher level of skill, learner internalization of processes being the eventual outcome. This study assessed the impact of student collaboration on comprehension.

In compliance with a request by the U.S. Congress, the National Institute of Child Health and Human Development of the National Institutes of Health in conjunction with the U.S. Secretary of Education established the National Reading Panel (NRP) to evaluate the efficacy of literacy instructional approaches. The NRP (2000) performed an analysis of a very limited number of investigations (only 38 experimental studies were included) on instruction pertaining to comprehension strategies. The panel concluded that eight strategies have strong empirical support. Among these was the use of collaborative learning groups wherein students have the opportunity to translate core class subject 
matter into the vernacular of the student. This investigation aimed at the use of collaboration to facilitate student interpretation of disciplinary text.

Additionally, research has indicated there is a need for modifying traditional classroom roles. For example, students should be taught to independently manage discussions of readings (Au \& Raphael, 2000), and that effective teachers not only develop critical thinking skills in their students but also group discussion skills (Sturtevant \& Linek, 2003). Student discussion, without teacher direction, may bring about enhanced text comprehension (Almasi \& Garas-York, 2009) along with greater student involvement and participation (Au \& Raphael, 2000). Van den Branden (2000) echoed this claim. He held that group discussion of text may, in addition to increasing comprehension, increase general reading skills and reader motivation. This study sought to assess these claims and in particular to develop independent learners.

Peer negotiation of meaning appears to be effective in disciplinary reading in general as well as in the discipline of science specifically. The use of collaborative groups has shown significant positive impact on comprehension of content area material by high school students (Biancarosa, 2005). Greater depth of understanding can result in that student collaboration pertaining to science texts necessitates that they construct, ponder, and alter their personal theories relative to science and their opinions must be orally expressed in small groups and supported through use of text information (Biancarosa, 2005). In this study, peer groups collaborate to discern text meaning.

Gambrell (2012) held that discussion of text leads to enhancement of critical thinking ability and comprehension, as well as the development of vocabulary. She reported findings that indicate student discussion results in higher scores on cognitive 
tests. Duke (2004) recommended small group peer interaction related to the reading of informational text. Larson (2011) stated that biology students working with partners and in small discussion groups report benefits relative to thought processes and comprehension of concepts, that instructing peers enhanced their own understanding, and that interaction was pleasurable. This investigation focused on peer discussion and its effect on student performance.

Greathouse and Lincoln (2008, p. 50) recommended small groups to facilitate the science learning of ELs. They maintained that thereby "students explain in their own words what they have learned, and extend and explore concepts in new situations." The Common Core State Standards Initiative (2015) defines text complexity in terms of three dimensions: reader and task, qualitative, and quantitative (see Appendix F). This model holds that the challenges of text can be mediated by use of familiar language to communicate concepts. Carrier (2005) held that student social interaction is beneficial to ELs' understanding of science. Developing science literacy by this means can enable students to comprehend print or Internet science articles and to offer descriptions, explanations, and predictions relative to natural phenomenon. The study analyzed the relationship between EL discussion groups, comprehension of text, and science learning.

There is benefit in combining students' pools of knowledge and varieties of discourse practices from both school and non-school sources to develop literacy skills and disciplinary text comprehension. Students shared out-of-school personal experiences and popular culture experiences (including, but not limited to, television, film, and Internet) can be utilized among peers as a foundation for understanding science concepts (Moje et al., 2004). In addition, research indicates that motivation can be enhanced by 
group work. Song and Grabowski (2006) reported findings that indicate learning-oriented peer groups have a greater effect on intrinsic motivation than goal-oriented peer groups. In an investigation by Saleh, Lazonder, and Jong (2005), students of various academic levels participating in a science activity were randomly placed into homogeneous or heterogeneous groups. Findings indicated low level students showed greater motivation and achievement in heterogeneous groups. This investigation employed student discourse to increase motivation and assessed its influence on comprehension of science text and concepts.

\section{Oral Language and Discussion}

There exists a symbiotic relationship between oral language development and small group discussion. Oral language encompasses skills related to phonology, morphology, grammar, vocabulary, discourse, and pragmatics. Vocabulary involves both expressive and receptive word skills. Discourse relates to communicating persuasively, grasping cause and effect, and the ability to compare and contrast. Pragmatics pertains to an awareness of and adeptness concerning the subtleties of conversational group dynamics (Crawford-Brooke, 2013). In addition, competence in the area of oral language necessitates listening comprehension (Geva \& Massey-Garrison, 2012).

Artley (1953) claimed that "a child can read no better than he [or she] can organize his [or her] ideas and express them" (p. 321). He explains this by stating that the reading process requires thought, interpretation, and response. These are skills that develop with oral language. Crawford-Brooke (2013) reported that students with oral language disabilities show up to a $500 \%$ greater incidence of literacy problems. 
Clarke, Snowling, Truelove, and Hulme (2010) conducted an investigation with a randomized sample of students with comprehension deficits. Three experimental groups and a control were utilized. One of the treatment groups received training related to enhancement of oral language skills. A second group received training in comprehension strategies. The third received instruction in both areas. All three groups showed significant gains in comparison to the control and an 11-month follow-up indicated that gains appeared to be maintained. Noteworthy is that the group receiving oral language intervention without comprehension instruction showed the greatest improvement.

Vernelson and Wilson (2011) held that at every grade level, oral language abilities are critical for learning in all academic areas including literacy. Baker (1968), over four decades ago, spoke of the importance of teaching students the effective use of oral language. Shining Star (2013) is a program of differential instruction for ELs in middle and high schools. Deficits in the comprehension of oral language are held to adversely affect comprehension of written language. Program goals are the development of oral language by means of instruction based on discussion and thereby the improvement of reading comprehension skills. Findings indicated increases in language ability and reading skills.

Soto-Hinman (2011) held that nationwide there is a need for instruction geared toward the development of oral language to enhance learning in content area classes as well as the learning of the English language. August (2002) claimed that not even two percent of the time spent in school by ELs is devoted to the development of oral language. Kirkland and Patterson (2005) concurred. They claimed that instruction relative to oral language acquisition "has been an incidental occurrence historically" (p. 391). 
They advised that the teacher act as facilitator to students' acquisition of skills, propose that student-to-student interaction socially play a major role, and note that efforts to comprehend the meaning of text can aid in growth.

The proposed study involved small group discussion of science text by high school students with varying degrees of English language proficiency to aid in their processing of ideas. Multiple factors impact the oral language of ELs including disruption to family life resulting from the immigration experience, the language spoken by family members in the household, and the quantity and quality of words in the personal lexicon (Crawford-Brooke, 2013). Discussion is recommended as a means of fostering oral language development (Shining Star, 2013) so as to facilitate the processing of ideas.

\section{Adolescent ELs, Collaboration, and Disciplinary Literacy}

Moje et al. (2004) proposed that ELs function in a "third space." They offered an explanation of this concept:

Hybridity theory posits that people in any given community draw on multiple resources or funds to make sense of the world and to make sense of oral and written texts. Further, hybridity theory examines how being in-between several different funds of knowledge and discourse can be both productive and constraining in terms of one's literate, social, and cultural practices and, ultimately, one's identity development. (p. 5)

This point of reference, perspective, or mode of thought that is not fully a product of any one community is referred to as "third space." 
The participants in this study occupy a third space. They are ELs, all of whom are Hispanic. Some are recent arrivals from any one of the many Spanish-speaking nations in the Western Hemisphere. Others, although born in the United States, entered school speaking Spanish rather than English. They attend a public high school where instruction is conducted in English. In addition, they are members of the Latino adolescent community that spans several predominantly Hispanic municipalities located within the boundaries of a large urban public school district in the Southeastern United States.

An investigation by Moje et al. (2004) focused on Hispanic secondary school students and disciplinary literacy in the science classroom. Numerous findings relate to this proposed study. Peer interaction had a significant effect on comprehension of textbooks. Experiences from informal peer activities, such as bicycle stunt riding, aided in understanding of physics concepts. Formal peer activities, such as those related to automobiles, provided insights into science. Popular culture (including sources such as television, movies, news media, print magazines, and music [this was prior to the proliferation of the Internet and smart phones]) provided funds of knowledge useful in the science classroom.

Moje et al. (2004) called for the development of new classroom strategies. They held there is a need for ones that will combine these funds of knowledge with those sought in the science classes. Student-led discussion small groups aimed at negotiating the meaning of physical science textbook material may be such a strategy.

Frank (2011) reported that science teachers interviewed believe that students who are ELs require literacy skill development and benefit from activities related to meaningmaking involving peer interaction including class conversations. Investigators concur that 
collaborative meaning negotiation can be of value to students with limited English proficiency. Student-conducted, unstructured discussion groups based on student questions relative to the read text can spur the participation of diverse students (Maloch, 2005). Au and Raphael (2000) maintained that student-to-student discourse can advance diverse student literacy development and that reading instruction reaps greater benefits. Interaction allows students to utilize oral language which is crucial for the development of academic vocabulary required for comprehension of text. In order for students to internalize comprehension strategies taught, opportunities for practice must be provided (Pressley, 2006) in small groups.

The Speaking and Listening Standards of the Common Core Standards establish the need for students to have experiences which will develop critical speaking and listening skills as well as those related to participation in cooperative learning groups. "They require students to build upon others' ideas, articulate their own ideas, and confirm understanding through informal collaborative group interactions" (Bunch, Kibler, \& Pimentel, 2012). As regards the area of science, ELs require the opportunity to contemplate ideas related to science and to then orally express their thoughts in English. Hence, peer discussion is an integral part of instruction considered to be best practice (Gersten \& Baker, 2000). The act of joint meaning negotiation can enable second language learners to grasp text that is beyond their degree of second language proficiency (Van den Branden, 2000). Research has shown that Hispanic students with greater English proficiency often aid those with a lesser degree of English fluency in regard to the reading of school texts (Moje et al., 2004) and that higher proficiency level readers 
can benefit from meaning negotiation activity with readers of less language proficiency (Van den Branden, 2000).

Researchers studying literacy instruction have the tendency to concentrate on instructional strategies that are successful in the laboratory but that lack ecological validity (Au \& Raphael, 2000). Ruddell and Unrau (2004, p. 1510) viewed "reading as a meaning-construction process" and advocated a "reality-based, classroom-centered model." The student interacts with the text based on an understanding of vocabulary and prior experiences and thereby interprets written material. In order for this to occur in a high school physical science, biology, chemistry, or physics class, a strategy must lend itself to the structure of the science classroom. In that lab teams are a customary component of science classes, text discussion groups may be a natural extension for the groups.

In as much as state and district pacing guides contain a substantial number of goals and objectives, there is a tendency among science teachers to perceive additional instructional tasks as burdensome (Halim et al., 2006). Hence to have true ecological validity (that is, to be feasible for use in a real world classroom, rather than merely in an artificial laboratory setting), an intervention must be easily implemented and not excessively time-consuming. Raphael and $\mathrm{Au}$ (2005) advocated the use of comprehension strategies that reap school-wide benefits but that require a minimal amount of instructional time and teacher effort. Furthermore, the literature indicates that there is a need for experimentation with in-class literacy endeavors. Activities should be developed that may act to fuse student prior knowledge and communication styles with 
academic information and academic modes to facilitate the comprehension of disciplinary text and concepts (Moje et al., 2004).

The International Reading Association (2006) stated that secondary school teachers need to learn how to instruct students in core area knowledge concurrently with instruction related to disciplinary literacy. The IRA claimed that by enhancing the latter, the former will be positively affected.

\section{Comprehension Strategy}

In The Report of the National Reading Panel: Teaching Children to Read, the NRP (2000) recommended summarization as an effective reading strategy. It noted that students are required to determine the main idea of a passage by the elimination of bits of information that are not pertinent. This necessitates text rereading which can facilitate comprehension.

Duke (2004) gave voice to the obvious in her statement that students of all ages show difficulty in the comprehension of text that is informational. She suggested various methods of remedying this situation. Among these is the explicit teaching of comprehension strategies including the summarization of text and the explanation of thought processes. In order for a passage to be summarized, cognitive processes must transpire involving analysis of printed material. Likewise, such processes are necessary for one to explain one's thinking and thus rationale for conclusions.

Federal and state policymakers and educational reformers must be aware that instruction in skills such as fluency and decoding should not be considered the responsibility of teachers of core content classes (science, mathematics, and social 
studies) but rather instruction in disciplinary text comprehension (Alliance, 2007). The need is for interventions that are truly ecologically valid, meaning easily implemented and, over the course of the school year, not labor intensive.

The goal of this investigation was to determine whether the treatment, which was implemented through disciplinary teachers, would improve textbook comprehension. The method corresponds to what Shanahan (2009, p. 253) refers to as science text structure research pertaining to "helping students use existing text structures to comprehend science texts." This strategy directs students toward processes identified by Pressley (2000) as being used by skilled readers including text overviewing and selective reading.

This study draws on many sources. It is patterned after Van den Branden's (2000) investigation involving fifth-grade students of Italian, Turkish, and Moroccan origin, who were learners of Dutch in Belgium. In that study, he utilized a researcher-composed multiple chapter short story, which focused on a topic determined to be of high interest to the participants. Students independently read the story, chapter by chapter. Upon completion of each chapter reading, text meaning was discussed in small groups. Immediately thereafter, a brief researcher-developed comprehension assessment was administered. The small discussion groups were managed by the researcher. Students were given neither a method by which to guide reading nor discussion.

His work was in part modified by incorporation of the academic conversation strategy (Zwier \& Crawford, 2011) which trains students in the skills necessary for managing and advancing academic conversations including language for prompting partners and for responding. Students were taught to clarify and elaborate upon one's own perspective, to further develop or challenge peers' perspectives, to paraphrase, to 
synthesize ideas, and to bolster opinions with evidence. Additionally, ground rules for interaction were established. In this investigation, the method was used not only to structure conversation, as per Zwier and Crawford (2011), but were extended further. It was used as a vehicle to organize individuals' thought processes regarding the text during independent reading and summarization, prior to group interaction.

The small group discussion format was based in part on the intra-act strategy developed by Hoffman (1979) in which small group, student leaders summarize and lead a discussion of a reading with members asking questions and contributing their thoughts. In the strategy used in this present study, each member independently composed a brief summary of chapter passages. Subsequently, all members participated in small group discussion of text read. Finally, depending upon the individual student's agreement with group conclusions, he or she may have opted to modify the independently composed summary. Fine (2012) has reported that discussion of text and student rephrasing text material improves comprehension.

Rather than high-interest, researcher-composed text, this investigation utilized a published, state-adopted, district-mandated physical science textbook currently in use in public school classrooms in a course required for high school graduation. It was implemented with ninth-grade EL students, whose first language is Spanish, in a large urban school district in the Southeastern United States. Van den Branden (2000) noted in that he used narrative text, there is a need for investigation with expository text. He also questioned the ecological validity of his method given that the treatment was not delivered by students' classroom teachers. He suggested future research to seek a means of lessening teacher input into student discussion of text (Van den Branden, 2000). 
Rather than researcher-developed instruments, this study used an American Association for the Advancement of Science Physical Science comprehensive examination. Small groups were student-led without teacher direction in that the treatment sought to develop independence in learning. The treatment was implemented by the students' teachers as part of instruction in their actual science classrooms. It is of a format that lends itself to incorporation into the lab-driven high school science class.

Investigators have reported that collaborative meaning negotiation can be of value to students with limited English proficiency. Student-conducted, unstructured discussion groups based on student questions relative to the read text can spur the participation of diverse students (Maloch, 2005) and student-to-student discourse can advance diverse student literacy development (Au \& Raphael, 2000).

\section{Summary}

This chapter reviewed relevant research related to English learners, adolescent literacy, disciplinary learning, science literacy, collaborative learning, and comprehension strategies. In addition, it examined literature related to gender and academic achievement as well as oral language and discussion. Research indicates that adolescent learners and ELs in particular may benefit from collaborative small groups and that disciplinary literacy may be developed via discussion which has a strong relationship with oral language development. Further, the literature suggests that boys have an aptitude toward science and girls toward language. 


\section{CHAPTER III}

\section{PROCEDURES}

The focus of this study was to investigate the relationship between independent summarization along with small group discussion, by English Learners (ELs), of state adopted physical science textbook material and achievement on an American Association for the Advancement of Science (AAAS) Physical Science comprehensive examination. To facilitate their negotiation of the meaning of text, students were trained in strategies which were utilized for summarization and discussion.

\section{Research Design}

The investigation employed a quasi-experimental, pretest-posttest design with comparison group. A sample of convenience was utilized in that individual students were not be recruited but rather classes as a whole participated.

\section{Treatment.}

Students silently read chapter material and individually composed summaries of passages read, which were handwritten in composition books. Following this, students discussed their summaries in small groups. Revisions were made as need be and a group summary was composed.

Groups included four to five students. Membership was determined by classroom teachers based on their knowledge of students' work habits, skill level, English language proficiency, and conduct. A participant could opt to speak English, Spanish, or a mix 
thereof. Students brought a researcher supplied notebook for independently composed and collectively revised passage summaries to the discussion group. One student, chosen by the teacher, presided but did not dominate.

Group guidelines included:

- Respect other people's ideas.

- All questions and comments were to be considered legitimate and necessary.

- The purpose was not to win an argument but instead to share ideas and to together interpret the textbook readings.

- Initially, each student in turn gave his or her response to a different section of a passage.

- Group members in turn asked for greater detail. Peers were permitted to contribute their perspectives.

- When a consensus was reached, each member as necessary, determined by the individual, revised his or her summary for a particular paragraph in his or her notebook.

- If there were dissenting opinions, ones different than the majority, dissenters were permitted to instead record an alternate interpretation.

Presiding student responsibilities included:

- Ensuring that the student given the floor was permitted to communicate his or her thoughts in an environment free of hostility.

- Ensuring that each student had a chance to respond to the text and to ask partners for more detail. 
- Ensuring that individuals did not dominate the discussion.

- Preventing excessive time from being spent on any one section

- Keeping students on task.

- The presiding student was not the final judge on the validity of an interpretation.

The following instructions were displayed on screen:

- By yourself, read the chapter in the book.

- When you finish reading a paragraph, write a short summary using the summarizing handout.

- In your small group (which I [the teacher] will organize), using the discussion handout, each person will share his or her response to a section of a passage. Each person will be given the chance to ask a speaker for more info. The group will discuss the ideas. People will share their thoughts based on their summaries. Together all group members will decide what the final version of each paragraph summary should include.

- Each member will submit his or her notebook containing the revised summary.

Intervention strategies which were utilized in this study are research-based. The specific approach was developed by this investigator. It is based on an intervention designed by Van den Branden (2000), on the academic conversations of Zwiers and Crawford (2011), and on the Ediger (2002) literacy circle strategy.

\section{Van den Branden study and this present study.}

Van den Branden's (2000) investigation involved fifth-grade students of Italian, Turkish, and Moroccan origin, who were learners of Dutch in Belgium. He utilized a 
researcher-composed multiple chapter short story, which focused on a topic determined by their classroom teachers to be of high interest to the participants. Students independently read the story, one chapter at a time. Upon completion of each chapter reading, text meaning was discussed in small groups. Immediately thereafter, a brief researcher-developed comprehension assessment was administered. The small discussion groups were managed by the researcher. Students were given neither a method by which to guide reading nor discussion.

This present study modified that of Van den Branden. It utilized a published, state-adopted, district-mandated physical science textbook currently in use in public school classrooms in a course required for high school graduation. It was implemented with ninth-grade EL students, whose first language is Spanish, in a large urban school district in the Southeastern United States. Van den Branden (2000) noted in that he used narrative text, there exists a need for investigation with expository text. He suggested that future research seek a means of lessening adult input into student discussion of text. He also questioned the ecological validity of his treatment, that is, whether it could be successfully delivered by classroom teachers during the normal course of school operations (Van den Branden, 2000).

Rather than researcher-developed instruments, this study used an American Association for the Advancement of Science Physical Science comprehensive examination. Small groups were student-led without teacher direction. The treatment was implemented by the students' teachers as part of instruction in their actual science classrooms. It is of a format that lends itself to incorporation into the lab-driven high school science class. 


\section{Academic conversations.}

Van den Branden's (2000) work was in part modified by this researcher by the incorporation and extension of the academic conversation strategy (Zwier \& Crawford, 2011). The method trains students in the skills necessary for managing and advancing discussions of academic topics (see Appendix D). Academic conversations are purposeful, sustained conversations on a subject area topic involving speaking, listening, and responding to partners. The strategy can develop core skills employed in academic conversations including elaboration and clarification, the support of ideas with evidence, extension or challenging of others' thoughts, synthesis of conversation points, and paraphrasing (Zwiers \& Crawford, 2011). It employs discourse moves which are phrases designed to focus and direct student analytical thought and communication. Examples include:

I think it means. An illustration of this could be. Yet I wonder. In other words. The evidence seems to suggest. What makes you think that? What is a real world example? What might be some other points of view? What do we know so far? What can we agree on? (Zwiers \& Crawford, 2011, p. 73).

In this investigation, the academic conversations method was used not only to structure conversation, but was extended further. It was used as a vehicle to organize individuals' thought processes regarding the text during independent reading and summarization, prior to group interaction. Students applied the discourse moves for oral academic conversations in a written form to organize thoughts on paper (see Appendix C). 


\section{Literacy circle.}

The format of the small groups was patterned in part after the literacy circle organization of Ediger (2002), in which groups are comprised of four or five students, who read and discuss text. Initially a leader is appointed by the classroom teacher. However, in the event of another leader arising or if a working democracy results, a modification of the leadership role is acceptable. Participation by all members is encouraged and expected. The goal is not to have domination by one or two participants. The goal is to develop a community of learners. Respect for thoughts and perspectives of peers is emphasized as critical. Discussion is required to be text-related. This researcher modified the literacy circle approach by including independent summarization of readings and a means by which students were able to approach both text and small group discussion.

\section{Derivation of Research Questions and Specific Research Hypotheses}

Much research has been published concerning the comprehension of content area text by students (Conley, 2009; Shanahan \& Shanahan, 2008). Science text and students with limited English proficiency have been focused upon in particular (Gagnon \& Abell, 2009; Fang, 2006). The impact of discussion of text, of peer interaction, and of comprehension strategy instruction relative to science text has been investigated (AAAS, 2013; Alliance, 2007; Biancarosa, 2005; Brown, 2011). Currently, there exists a great interest in the field of literacy research related to adolescents. Further, there is national concern regarding the literacy development of the increasing numbers of students with limited English proficiency. Compounding the situation, of late, school districts are 
seeing the development of state mandated standardized tests in science. In light of these factors, this researcher sought to investigate an ecologically sound intervention (one that can be implemented in an actual classroom rather than merely a laboratory setting) employing secondary school science text comprehension strategy instruction and structured student-conducted discussion groups with ELs.

\section{Research questions and specific research hypotheses.}

Hence the following general research question was developed:

General Research Question: Is the use of student-led discussion in small groups in conjunction with independent summarization of readings, as part of standards-based instruction, more effective in teaching physical science to ninth-grade EL students than standards-based instruction without student-led discussion in small groups, in conjunction with independent summarization of readings, and are there any interactions between instructional method and selected students' characteristics in determining physical science achievement?

In addition, the following research questions and specific research hypotheses were developed:

Research question 1. Will physical science achievement of ninth-grade EL students participating in student-led discussion-based small groups in conjunction with independent summarization of readings, as part of standards-based instruction, be greater than the physical science achievement of students who are taught using standards-based instruction without student-led discussion-based small groups in conjunction with independent summarization of readings? 
Specific hypothesis 1. The mean test scores on a post-treatment AAAS Physical Science comprehensive examination of ninth-grade ELs who participate in student-led discussion-based small groups in conjunction with independent summarization of readings, when adjusted for pre-treatment AAAS scores, will be significantly higher than adjusted mean test scores of ninth-grade ELs who do not participate in the intervention.

Research question 2. Is there a significant interaction between treatment and level of prior science knowledge in determining the scores of EL students on an $A A A S$ Physical Science comprehensive examination?

Specific hypothesis 2 . There is a significant interaction between treatment and level of prior science knowledge as measured by the eighth-grade FCAT 2.0 Science in determining the scores of EL students on a post-treatment AAAS Physical Science comprehensive examination when these scores are adjusted for pre-treatment AAAS scores.

Research question 3. Is there a significant interaction between treatment and reading level in determining the scores of EL students on an AAAS Physical Science comprehensive examination?

Specific hypothesis 3. There is a significant interaction between treatment and reading level as measured by the Florida Standards Assessments English Language Arts (FSA ELA) in determining the scores of EL students on a post-treatment AAAS Physical Science comprehensive examination when these scores are adjusted for pre-treatment AAAS scores. 
Research question 4. Is there a significant interaction between treatment and level of English language proficiency in determining the scores of EL students an $A A A S$ Physical Science comprehensive examination?

Specific hypothesis 4 . There is a significant interaction between treatment and level of English language proficiency as measured by the Comprehensive English Language Learning Assessment (CELLA) in determining the scores of EL students on a post-treatment AAAS Physical Science comprehensive examination when these scores are adjusted for pre-treatment AAAS scores.

Research question 5. Is there a significant interaction between treatment and students' gender in determining the scores of EL students on an AAAS Physical Science comprehensive examination?

Specific hypothesis 5. There is a significant interaction between treatment and students' gender in determining the scores of EL students on a post-treatment $A A A S$ Physical Science comprehensive examination when these scores are adjusted for pretreatment AAAS scores.

Research question 6. What are the perceptions of teachers relative to the intervention?

\section{Participants}

Two types of participants were involved in this study. High school students made up the treatment and comparison groups. Their classroom teachers, who implemented the investigation, were interviewed concerning perceptions of the treatment and their demographic factors. 


\section{Students.}

Subjects in this investigation were adolescents classified by their school district as ninth-graders currently enrolled in physical science classes. Ninety-six students were included in the original sample. At the end of the investigation, posttest scores were not available for 20 students. In addition, one student's pretest and posttest scores were discarded due to noncompliance during testing. Consequently, the final sample size was 75.

The treatment group was made up of 39 subjects, 22 boys and 17 girls. The comparison group was made up of 36 subjects, 21 boys and 15 girls. Participants were English Learners whose first language was Spanish. The high school in which the research was conducted was located in a community which is predominantly Hispanic.

Ages ranged from 14 to 16 years. All students had a degree of limited English proficiency. English learners are defined as students in American schools whose language spoken at home is not English and whose language proficiency is not considered fluent (Heineke, 2014). The home language of subjects was Spanish. ESOL department data, CELLA scores, were used to determine upon which of the five ESOL levels a student is classified. Levels are based on composite scores for the listening, speaking, reading, and writing sections of the CELLA (MDCPS ESOL, 2015; FDOE CELLA, 2015). Demographic data were collected for both experimental and comparison group members. Student membership was with parent consent and student assent. Pretest scores, eighthgrade FCAT 2.0 Science results, eighth-grade Florida Standards Assessments English Language Arts reading results, CELLA results, and gender were recorded. 


\section{Teachers.}

Two physical science teachers from a high school with predominately Hispanic student population participated. Each teacher conducted an experimental and a comparison group. Teacher perceptions of the treatment were recorded as well as data related to educational background, training, and experience (see Appendix B).

\section{Classroom teacher training.}

Students' science class teachers implemented the strategy. Teachers were trained by the researcher (see Appendix G.). Training was based on suggestions by Bennet, Hogarth, Lubben, Campbell, and Robinson (2010, p.69) who reported that "teachers and students need to be given explicit training in the skills associated with the development of arguments and the characteristics associated with effective group discussions."

Both teachers participated in the same 30-minute training in which a scripted lesson and treatment guidelines were presented. The script was comprised of strategies the researcher developed when implementing the treatment in his ninth grade physical science classes in another predominantly Hispanic public high school in the same district.

At this time, composition books and discourse moves (Zwiers \& Crawford, 2011) handouts for students were supplied. In addition, teachers were given flash drives for use in the classroom, when implementing the intervention, which included the scripted lesson used in training, small group guidelines, and step-by-step instructions for students. Both classrooms were equipped by the district with Promethean Boards, projectors utilized with desk top computers. 
Aspects of the study addressed were:

- The purpose of the treatment.

- The need for fidelity of treatment.

- Use of student composition books.

- Use of academic conversations discourse moves (Zwiers \& Crawford, 2011) for summarization of text and discussion.

- Redirection of students without interference in small group discussion.

In the event that students opted to participate in activities unrelated to independent text summarization and academic discourse, teachers were to address the situation. Such off-task behaviors include conversations that were strictly social, use of cell phones for texting or gaming, working on other assignments, daydreaming, or sleeping. Teachers were to redirect students to on-task work without providing prompts or modeling related to either summarization or discourse.

Questions and comments were encouraged throughout. If, based on perceptions during the training, there appeared a need for further training another session would have been requested. Criterion for further training was an apparent lack of comprehension of treatment strategies. Verbal exchanges appeared to indicate a grasp of the intervention by the teachers.

\section{Research Setting}

The study took place in public high school science classes in a large urban public school district in the Southeastern United States. The state and district mandated approach to teaching science at the secondary school site in which the investigation took 
place was standards-based, that is, in accordance with Common Core State Standards (2013) and Next Generation Science Standards (NSTA Guide, 2015; NSTA Next, 2015). Generally, instruction was delivered via technological resources, lectures, independent textbook readings, written classwork and homework, and lab experiences. Technological resources for teacher classroom instruction can be accessed through the employee portal of the district website. Discovery Education, Learning Village, NBC Learn K-12, and Gizmo are readily available, as are Promethean Board resources. The basis for student evaluation can include a state or district end of course examination, district quarterly assessments, lab reports, research papers, science projects, publisher and teacher-created tests, written responses to questions appearing in textbook chapters, as well as workbook and handout materials.

\section{Implementation of the Study}

This study commenced after the second grading period of the school year. The rationale for this decision was that classes are not leveled (that is, new classes are not opened so as to decrease class sizes) and scheduling errors are not corrected until the middle of the first nine-week grading period. Schedule changes generally take a number of weeks to be completed. Therefore, rosters may not be stabilized until well into the second grading period.

The study encompassed 11 consecutive school weeks. The school site utilized a scheduling format wherein students took eight courses. On alternating days, students attended four classes. Each period was 90 minutes. Consequently, during a school week 
in which no holidays or teacher work days occurred, students were in physical science class either twice or three time a week.

The investigation was conducted from the third week of the third grading period through the second week of the fourth grading period. State assessments in secondary schools began that week and were administered until late in the fourth and final grading period (see Appendix H).

Each session lasted less than one hour. During the first session, prior to treatment, an AAAS Physical Science comprehensive examination (AAAS Tests, 2015) was administered as a pretest. In the second session, treatment group students received instruction relative to guidelines and techniques for academic discussions (Zwiers \& Crawford, 2011) of textbook material as well as summarization strategies. Summarization techniques drew on those developed by Brown and Day (1983) and employed an extension of the academic conversations strategy of Zwier and Crawford (2011). Time was allowed for practice. Readings included an Internet article and textbook passages related to material covered earlier in the school year (see Appendix G). During this time, the comparison group reviewed the same textbook material through independent reading, copying text vocabulary definitions, answering textbook questions in writing, and completing handouts.

In each of the following treatment sessions, the facilitator, the students' classroom teacher, briefly reviewed the procedures for summarization and academic conversation strategies. Following this, participants read textbook chapter sections silently and each independently composed a summary. Upon competition, small groups discussed independent interpretations and rationale. Individuals opted to make modifications to 
independently-written summaries as they deemed necessary. As previously, during this time, the comparison group independently read text, copied text vocabulary definitions, answered textbook questions in writing, completed text publisher handouts, and utilized text publisher workbooks (see Appendix I).

During the last session, the AAAS Physical Science comprehensive examination (AAAS Tests, 2015) was again administered. Researcher observations of treatment groups occurred during the $10^{\text {th }}$ session (see Appendix A). The purpose was to document degree of fidelity of implementation by determining conformity to the teacher script (see Appendix G) and whether, when necessary, teachers redirect off task individuals and groups; whether teachers refrain from interfering with small groups by participating; to document the circumstances of any disciplinary incidents; and unanticipated events such as fire drills, power outages, and failure of air conditioning systems.

Student scores on posttests were analyzed in connection with their eighth-grade reading scores on the FDOE's Florida Standards Assessments English Language Arts. Posttest scores were also analyzed relative to students' eighth-grade FCAT 2.0 Science scores and to CELLA data. In addition, posttest results were compared on the basis of student gender.

\section{Teacher interviews.}

At the end of the study, teachers were given an interview regarding perceptions concerning the intervention as well as educational background, teacher training, and classroom experience (see Appendix B). The duration of the individual interviews was 
brief, not more than five minutes. Time constraints did not allow extensive probing. An open-ended qualitative format was used (Bogdan \& Biklen, 2007; Rubin \& Rubin, 2012).

Interview data relative to perceptions were collected in that research indicates there is value in receiving teacher feedback on newly developed methods of instruction. For example, Richardson (2003) reported that teacher decisions concerning the worth of a new instructional strategy depend on factors such its propensity to increase achievement on assessments and the level of engagement of students. Klingner, Ahwee, Pilonieta, and Menendez (2003) maintained that in order for a strategy to be adopted, teachers must witness its viability with and benefits to their students. Kent (2004) indicated that the teacher perceptions of a new strategy will determine acceptance thereof.

Teacher demographic data were collected relative to training in science education and to extent of experience in the public school classroom. Such factors may have an effect on teacher perspectives on the treatment both prior to and following implementation. The ability to manage a class in which a new strategy was introduced midyear might also be effected.

\section{Instruments}

Numerous instruments were utilized for data collection (see Appendix J). Achievement was analyzed relative to student knowledge of physical science, prior science knowledge, reading level, and English proficiency level. English learners were defined as students in American schools whose language spoken at home is not English and whose language proficiency is not considered fluent (Heineke, 2-014). The home language of subjects was Spanish. 


\section{AAAS Physical Science comprehensive examination.}

The instrument which was administered to assess achievement in physical science was an American Association for the Advancement of Science Physical Science comprehensive examination. It was used as both a pre- and posttest. The State of Florida has implemented the New Generation Science Standards (FDOE Bureau, 2014) and this instrument assesses the related benchmarks. Although the state has piloted a physical science end-of-course examination, copies of the instrument are not available.

The AAAS is an international organization founded in the United States in 1848. Its mission pertains to the advancement of innovation in the fields of science and engineering across the globe for the benefit of all people. Among its goals is the furtherance of science education (AAAS History, 2016). AAAS test items are the product of a two-year process of item design and item revision. Items were piloted and field tested nationally. Over 2,000 middle and high school students participated in pilot and field testing. Test item development involved AAAS staff, dozens of reviewers, more than 1,000 teachers, and over 150,000 students (AAAS Assessment, 2016).

\section{The FCAT 2.0 Science.}

Data relative to prior science knowledge were taken from eighth-grade scores on the 2015 FCAT 2.0 Science assessment. According to the Florida Statewide Assessments 2013 Technical Report (FDOE FCAT, 2013), content validity was measured using a root mean square error of approximation (RMSEA), the confirmatory fit index (CFI), and the Tucker Lewis index (TLI). These models compare hypothesized values with the actual values. The RMSEA was 0.015 . Values close to zero are preferable. The CFI was equal to 0.986 and the TLI was equal to 0.986 . For these indexes, values close to 1.0 are 
preferable. (Rigdon, 1996). Test items were field tested by inclusion in the FCAT Science test prior to the initial administration of the FCAT 2.0 Science. The internal consistency reliability measured by the Cronbach alpha was estimated to be 0.913 . Its marginal reliability was 0.941 (FDOE FCAT 2.0, 2013). Posttests scores on the American Association for the Advancement of Science Physical Science comprehensive examination were compared to FCAT 2.0 Science levels.

The Florida Standards Assessment English Language Arts.

Data relative to literacy skills were taken from eighth-grade scores on the 2015 Florida Standards Assessments English Language Arts (FSA ELA). In its report entitled Florida Standards Assessment 2014-2015, Volume 4: Evidence of Reliability and Validity (FDOE FSA, 2015), the FDOE maintains that reliability was measured with the Cronbach alpha testing for internal consistency. Alpha equaled 0.92 . Validity was ensured by the development of blueprints designed to provide assurance that the overall test and individual test items were in alignment with the standards targeted for assessment. Posttests scores on the American Association for the Advancement of Science Physical Science comprehensive examination were compared to FSA ELA reading levels.

The Comprehensive English Language Learning Assessment.

Relevant school site data from the 2015 Comprehensive English Language Learning Assessment (CELLA) were accessed. The instrument was developed by the Educational Testing Service (ETS) in 2005 and was tested for reliability and validity. Psychometric characteristics are presented in the Florida Comprehensive English Language Learning Assessment Technical Report Summary for the Spring 2014 Administration (Questar, 2014) and the CELLA Technical Report Summary, July 2005 
(CELLA ETS, 2005). Regarding reliability, scales for the four sections range from 0.90 to 0.95 . Content validity is acceptable. The assessment is used to measure the proficiency of students enrolled in ESOL classes, strengths and weaknesses, and readiness to exit from the program. In addition to speaking and listening skills, it tests reading and writing ability (FDOE CELLA, 2014). Posttests scores on the American Association for the Advancement of Science Physical Science comprehensive examination were compared to CELLA English proficiency levels.

\section{Additional Sources of Data Collection}

Other sources of data collection were used. Data pertained to student gender, fidelity of treatment, teacher demographics, and teacher perceptions.

\section{Student gender.}

Data related to gender were acquired via school site records. Posttests scores on the American Association for the Advancement of Science Physical Science comprehensive examination were analyzed in regard to gender.

\section{Observation of treatment groups.}

A classroom observation form was used to measure treatment fidelity during implementation of the intervention. It was researcher-designed in that particular behaviors were sought, notably adherence to the script as well as a mix of noninterference and redirection. It also documented any extraneous factors that occurred that may have impacted the learning environment such as interruptions by PA announcements, assistant principals, or security personnel (see Appendix A). 


\section{Teacher perceptions of treatment and demographic factors.}

A teacher interview was conducted concerning perceptions of the treatment as well as educational background, teacher training, and classroom experience (see Appendix B). It was researcher-developed in accordance with guidelines by Rubin and Rubin (2012) and by Bogdan and Biklen (2007).

\section{Variable List}

This investigation involved five independent variables. Their impact on one dependent variable was analyzed.

The independent variables were:

- Group membership: Both groups received standards-based instruction. The treatment groups participated in an intervention incorporating silent reading in conjunction with independently-written summaries, using written academic conversation guidelines, followed by student-conducted discussion using academic conversations of text and a revision of summaries. The comparison groups read silently and completed publisher-designed materials including workbooks, handouts, vocabulary lists, and textbook questions.

- Reading level as measured by eighth-grade Florida Standards Assessments English Language Arts scores

- Background knowledge in science as measured by eighth-grade FCAT 2.0 Science scores

- English language proficiency as measured by eighth-grade CELLA scores

- Gender (male, female) as recorded in district records 
The dependent variable was:

Achievement in physical science as measured by American Association for the Advancement of Science Physical Science comprehension examination posttest scores

\section{Data Collection}

Students' classroom teachers administered the AAAS Physical Science pretest and posttest. Copies of the student answer sheets were submitted to the researcher. FCAT 2.0 Science, Florida Standards Assessment English Language Arts, and CELLA scores in addition to data on student gender were acquired through school records;

During session 10, researcher observations of treatment groups were conducted. Data were recorded related to treatment fidelity and classroom interruptions (see Appendix A).

At the conclusion of the study, the researcher gathered data related to teacher demographics including educational background, teacher training, and classroom experience. Additionally, teacher perceptions of the treatment were recorded (see Appendix B).

\section{Statistical Treatment}

Specific hypothesis 1 was tested using an analysis of covariance with the pretreatment $A A A S$ Physical Science comprehensive examination scores as the covariate, the posttreatment AAAS Physical Science comprehensive examination scores as the dependent variable, and teaching method as the independent variable. The hypothesis was tested at the alpha $=.05$ level of significance. 
Specific hypothesis 2 was tested using a factorial analysis of covariance. The pretreatment AAAS Physical Science comprehensive examination scores were the covariate, the posttreatment AAAS Physical Science comprehensive examination scores were the dependent variable, and teaching method and level of prior science knowledge (measured by the eighth-grade FCAT 2.0 Science assessment) were the independent variables. The hypothesis for interaction between the independent variables in determining the dependent variable was tested at the alpha $=.05$ level of significance.

Specific hypothesis 3 was tested using a factorial analysis of covariance. The pretreatment AAAS Physical Science comprehensive examination scores was the covariate, the posttreatment AAAS Physical Science comprehensive examination scores was the dependent variable, and teaching method and reading level (measured by the eighth-grade Florida Standards Assessments English Language Arts [FSA ELA]) were the independent variables. The hypothesis for interaction between the independent variables in determining the dependent variable was tested at the alpha $=.05$ level of significance.

Specific hypothesis 4 was tested using a factorial analysis of covariance. The pretreatment AAAS Physical Science comprehensive examination scores was the covariate, the posttreatment AAAS Physical Science comprehensive examination scores was the dependent variable, and teaching method and level of English language proficiency (measured by the Comprehensive English Language Learning Assessment [CELLA]) were the independent variables. The hypothesis for interaction between the 
independent variables in determining the dependent variable was tested at the alpha $=.05$ level of significance.

Specific hypothesis 5 was tested using a factorial analysis of covariance. The pretreatment AAAS Physical Science comprehensive examination scores was the covariate, the posttreatment AAAS Physical Science comprehensive examination scores was the dependent variable, and teaching method and student gender were the independent variables. The hypothesis for interaction between the independent variables in determining the dependent variable was tested at the alpha $=.05$ level of significance.

Considering possible consequences, the rationale for testing each of the hypotheses at the alpha $=.05$ level of significance was that for each hypothesis a Type II error was preferable over a Type I error. The .05 level is customarily employed in behavioral science investigations. The use of a .05 level results in a probability that a relationship observed between the independent and dependent variables is by chance is 1 in 20 or less. A .001 level would result in a probability of 1 chance in 1,000 or less, which is extremely conservative. A .10 level would result in a probability of 1 in 10 or less, this does not provide adequate assurance. Rejection of a treatment that may be productive, in this case, is less desirable than erroneously retaining a treatment that is ineffective. At this point, a Type II error will not adversely affect the educational progress of students or the budgets of school districts. In addition, future investigations related to this treatment are planned (Ary, Jacobs, \& Sorensen, 2010; Charles \& Mertler, 2002; Hinkle, Wiersma, \& Jurs, 2003). 


\section{Summary}

The study utilized a quasi-experimental design with comparison groups. It examined the relationship between independent silent reading and summarization of state adopted physical science textbook material in conjunction with student-led small group discussion by ELs and their achievement on an American Association for the Advancement of Science Physical Science comprehensive examination The oral academic conversations discourse moves of Zwiers and Crawford (2011) were used to structure discussion and were extended to guide the summarization process so as to facilitate student negotiation of the meaning of text. Achievement was analyzed relative to prior science knowledge, reading level, ESOL level, and gender. 


\section{CHAPTER IV}

\section{RESULTS}

The primary focus of this present investigation was to examine the effect of independent summarization of silently read state-adopted physical science textbook material followed by student-led discussion and revision of summaries in small groups, comprised of ninth-grade English Learners, on the comprehension of science text. The study also examined the impact of the treatment in regard to students' background knowledge in science, reading level, degree of English language proficiency, and gender.

Quantitative and qualitative methods were employed. Statistical analysis of preand posttests science scores was conducted. Results were analyzed in respect to prior science knowledge, reading proficiency, English for Speakers of Other Languages (ESOL) level, and gender. Qualitative interview methods were used to record teacher perception of treatment and demographic factors.

\section{Overview of Study}

Ninety-six students, who were enrolled in the school district's ninth-grade physical science classes, were included in the original sample. At the end of the investigation, posttest scores were not available for 20 students. In addition, one student's pretest and posttest scores were discarded due to noncompliance during testing. Consequently, the final sample size was 75 .

The treatment group was made up of 39 students, 22 boys and 17 girls. The comparison group was made up of 36 students, 21 boys and 15 girls. Participants were 
English Learners whose first language was Spanish. The high school in which the research was conducted was located in a community which is predominantly Hispanic.

The study was implemented by the students' physical science teachers during class time. Each teacher had a treatment group and a comparison group. In order to assess achievement in physical science, students sat for a pretest prior to treatment and a posttest following treatment. The 53 multiple choice items were developed by the American Association for the Advancement of Science (AAAS Test, 2015) and addressed benchmark topics required by the district and state in accordance with the Common Core State Standards (Common Core, 2013) and the Next Generation Science Standards of the National Science Teachers' Association (NSTA Next, 2015). Numerical scores were utilized.

The teachers trained treatment group students in a strategy by which to independently compose summaries of silently read passages from a state-adopted physical science textbook as well as in a strategy for independently conducting small group discussion of text. During discussions, students collaboratively revised summaries as necessary. Teachers followed a script the researcher had presented prior to commencement of the study.

During the sessions that followed, in which the students independently implemented the strategy, teachers were instructed to adhere to the guidelines, as when proctoring a state assessment. Students were not to be given help in summarization of text or in small group discussion thereof. 
The duration of the investigation was 11 weeks. The researcher observed treatment groups during week 10. At the conclusion of the study, teachers responded to interview questions concerning demographic factors and perceptions of the treatment.

\section{Statistical Analysis of Data}

The initial analysis of data was related to the comparison of gains in American Association for the Advancement of Science Physical Science test scores of the treatment group with those of the comparison group. This involved an analysis of covariance with the pretreatment AAAS examination scores as the covariate, the posttreatment scores as the dependent variable, and the teaching method as the independent variable. This was tested at the alpha $=.05$ level of significance.

Analysis of pretest and posttest scores relative to students' science, reading, and English language proficiency levels as well as students' gender involved a factorial analysis of covariance. Pretreatment AAAS scores was the covariate, posttreatment AAAS scores was the dependent variable, teaching method and accordingly either eighthgrade FCAT 2.0 Science scores, eighth-grade Florida Standards Assessment English Language Arts scores, Comprehensive English Language Assessment scores, and gender were the independent variables. Interactions between the pair of independent variables in determining the dependent variable were tested at the alpha $=.05$ level of significance.

\section{Results of Testing Research Hypotheses}

Each hypothesis was evaluated through the utilization of quantitative data analysis. A verbal explanation of the results is presented in Appendix K. 


\section{Results of testing research hypothesis one.}

Hypothesis 1

The mean test scores on an AAAS Physical Science comprehensive examination of ninth-grade ELs who participate in student-led discussion-based small groups in conjunction with independent summarization of readings, when adjusted for pretreatment $A A A S$ scores, will be significantly higher than adjusted mean test scores of ninth-grade ELs who do not participate in the intervention.

Table 1 presents the descriptive statistics for the AAAS Physical Science pretest and posttest scores of the participants broken down by treatment group.

Table 1

Descriptive Statistics of the AAAS Physical Science Examination $(N=75)$

\begin{tabular}{lccccc}
\hline \multirow{2}{*}{ Group } & \multicolumn{2}{c}{ Pretest } & & \multicolumn{2}{c}{ Posttest } \\
\cline { 2 - 3 } \cline { 5 - 6 } & $M$ & SD & & $M$ & SD \\
\hline Academic conversation & 19.230 & 7.828 & & 21.21 & 6.578 \\
Publisher Materials & 22.505 & 9.581 & & 23.44 & 9.581 \\
\hline
\end{tabular}

Table 2 is the source table for the analysis of covariance that was performed to test Hypothesis 1. It indicates that no significant difference was found between the means of the two groups $(p=.994)$.

Table 2

Analysis of Covariance AAAS Posttest Science Scores Instructional Method With Pretest Scores as Covariate

\begin{tabular}{lrrrrrr}
\hline \multicolumn{1}{c}{ Source } & $d f$ & \multicolumn{1}{c}{ SS } & \multicolumn{1}{c}{ MS } & \multicolumn{1}{c}{$F$} & $p$ & \multicolumn{1}{c}{$\eta^{2}$} \\
\hline AAAS science pretest & 1 & 2008.009 & 20008.009 & 50.742 & $<.001$ & .413 \\
Group & 1 & .002 & .002 & $<.001$ & .994 & $<.001$ \\
Error & 72 & 2849.239 & 39.573 & & & \\
$\quad$ Total & 74 & 4951.120 & & & & \\
\hline
\end{tabular}




\section{Results of testing research hypothesis two.}

\section{Hypothesis 2}

There is a significant interaction between treatment and level of prior science knowledge as measured by the eighth-grade FCAT 2.0 Science in determining the scores of EL students on an AAAS Physical Science comprehensive examination when these scores are adjusted for pre-treatment $A A A S$ scores.

Table 3 presents the descriptive statistics for the pretest and posttest $A A A S$ Physical Science examination and the participants' scores on the FCAT 2.0 Science examination.

Table 3

Descriptive Statistics of the ASSS Physical Science examination and FCAT 2.0 Science $(N=47) *$

\begin{tabular}{|c|c|c|c|c|c|c|}
\hline \multirow[b]{2}{*}{ Group } & \multicolumn{2}{|c|}{$\begin{array}{c}\text { Pretest } \\
\text { AAAS Science }\end{array}$} & \multicolumn{2}{|c|}{$\begin{array}{c}\text { Posttest } \\
\text { AAAS Science }\end{array}$} & \multicolumn{2}{|c|}{$\begin{array}{c}\text { FCAT } 2.0 \\
\text { Science } \\
\end{array}$} \\
\hline & $M$ & $S D$ & $M$ & $S D$ & $M$ & $S D$ \\
\hline Academic conversations & 18.89 & 7.089 & 21.21 & 6.578 & 1.71 & .600 \\
\hline Publisher materials & 20.89 & 8.259 & 23.44 & 9.581 & 2.00 & .745 \\
\hline
\end{tabular}

*Note: N's may vary because of unavailability of FCAT 2.0 Science scores for some students

Table 4 is the source table for the analysis of covariance that was performed to test Hypothesis 2. No significant interaction was found between the treatment received by participants and their FCAT 2.0 Science examination scores in determining the AAAS Physical Science posttest scores $(p=.959)$. 
Table 4

Analysis of Covariance AAAS Physical Science Posttest scores, FCAT 2.0 Science scores, and

Instructional Method With AAAS Physical Science Pretest Scores as the Covariate

\begin{tabular}{lrrrrrr}
\hline \multicolumn{1}{c}{ Source } & \multicolumn{1}{c}{ Sf } & \multicolumn{1}{c}{ SS } & \multicolumn{1}{c}{ MS } & \multicolumn{1}{c}{$F$} & \multicolumn{1}{c}{$p$} & \multicolumn{1}{c}{$\eta^{2}$} \\
\hline AAAS science pretest & 1 & 1391.387 & 1391.387 & 33.303 & $<.001$ & .462 \\
Group (G) & 1 & .002 & .002 & $<.001$ & .994 & $<.001$ \\
FCAT science (F) & 2 & 7.032 & 3.516 & .087 & .917 & .004 \\
G $\times$ F & 2 & 3.442 & 1.721 & .042 & .959 & .002 \\
Error & 40 & 1622.450 & 40.461 & & & \\
$\quad$ Total & 46 & 3249.277 & & & & \\
\hline
\end{tabular}

\section{Results of testing research hypothesis three.}

Hypothesis \#3

There is a significant interaction between treatment and reading level as measured by the Florida Standards Assessments English Language Arts (FSA ELA) in determining the scores of EL students on an AAAS Physical Science comprehensive examination when these scores are adjusted for pre-treatment $A A A S$ scores.

Table 5 presents the descriptive statistics for participants' AAAS Physical Science examination pretest and posttest scores and their scores on the FSA ELA (reading).

Table 5

Descriptive Statistics of the ASSS Physical Science examination and FSA ELA Reading $(N=48) *$

\begin{tabular}{|c|c|c|c|c|c|c|}
\hline \multirow[b]{2}{*}{ Group } & \multicolumn{2}{|c|}{$\begin{array}{c}\text { Pretest } \\
\text { AAAS Science }\end{array}$} & \multicolumn{2}{|c|}{$\begin{array}{c}\text { Posttest } \\
\text { AAAS Science }\end{array}$} & \multicolumn{2}{|c|}{$\begin{array}{l}\text { FSA ELA } \\
\text { Reading }\end{array}$} \\
\hline & $M$ & $S D$ & $M$ & $S D$ & $M$ & $S D$ \\
\hline Academic conversations & 19.48 & 7.084 & 21.21 & 6.578 & 32.93 & 2.811 \\
\hline Publisher materials & 22.16 & 7.731 & 23.44 & 9.581 & 24.74 & 1.422 \\
\hline
\end{tabular}

*Note: N's may vary because of unavailability of FSA ELA (reading) scores for some students 
Table 6 is the source table for the analysis of covariance that was performed to test Hypothesis 3. No significant interaction was found between the treatment received by participants and their FSA ELA (reading) scores in determining the AAAS Physical Science posttest scores $(p=.425)$.

Table 6

Analysis of Covariance Using Reading Level and Instructional Method With AAAS Science Pretest Scores as Covariate

\begin{tabular}{lrrrrrl}
\hline \multicolumn{1}{c}{ Source } & $d f$ & \multicolumn{1}{c}{ SS } & \multicolumn{1}{c}{ MS } & \multicolumn{1}{c}{$F$} & \multicolumn{1}{c}{$p$} & $\eta^{2}$ \\
\hline AAAS science pretest & 1 & 511.355 & 511.355 & 14.399 & $<.001$ & .251 \\
Group (G) & 1 & 94.332 & 94.332 & 2.656 & .110 & .058 \\
Reading group (R) & 1 & 5.308 & 5.308 & .149 & .701 & .003 \\
G $\times$ R & 1 & 24.078 & 24.078 & .678 & .425 & .016 \\
Error & 43 & 1527.021 & 35.512 & & & \\
$\quad$ Total & 47 & 2473.917 & & & & \\
\hline
\end{tabular}

\section{Results of testing research hypothesis four.}

\section{Hypothesis 4}

There is a significant interaction between treatment and level of English language proficiency as measured by the Comprehensive English Language Learning Assessment (CELLA) in determining the scores of EL students on an AAAS Physical Science comprehensive examination when these scores are adjusted for pre-treatment $A A A S$ scores.

Table 7 presents the descriptive statistics for participants' AAAS Physical Science examination pretest and posttest scores and their ESOL levels are measured by the CELLA. 
Table 7

Descriptive Statistics of the ASSS Physical Science examination and ESOL Level $(N=65) *$

\begin{tabular}{|c|c|c|c|c|c|c|}
\hline \multirow[b]{2}{*}{ Group } & \multicolumn{2}{|c|}{$\begin{array}{c}\text { Pretest } \\
\text { AAAS Science }\end{array}$} & \multicolumn{2}{|c|}{$\begin{array}{c}\text { Posttest } \\
\text { AAAS Science }\end{array}$} & \multicolumn{2}{|c|}{ ESOL } \\
\hline & $M$ & $S D$ & $M$ & $S D$ & $M$ & $S D$ \\
\hline Academic conversations & 18.81 & 6.973 & 21.21 & 6.578 & 4.11 & 1.687 \\
\hline Publisher materials & 21.62 & 7.785 & 23.44 & 9.581 & 3.62 & 1.879 \\
\hline
\end{tabular}

*Note: N's may vary because of unavailability of CELLA scores for some students

Table 8 is the source table for the analysis of covariance that was performed to test Hypothesis 4. The analysis revealed an interaction between participants' treatment group and their ESOL group scores in determining AAAS Physical Science posttest scores. The significant interaction accounts for $6.5 \%$ of the variance between the posttest scores of the two groups.

Table 8

Analysis of Covariance Using ESOL Level and Instructional Method With AAAS Physical Science Pretest Scores as Covariate

\begin{tabular}{lrrrrrr}
\hline \multicolumn{1}{c}{ Source } & $d f$ & \multicolumn{1}{c}{ SS } & \multicolumn{1}{c}{ MS } & \multicolumn{1}{c}{$F$} & \multicolumn{1}{c}{$p$} & $\eta^{2}$ \\
\hline AAAS science pretest & 1 & 930.142 & 930.142 & 26.786 & $<.001$ & .309 \\
Group (G) & 1 & 94.332 & 94.332 & 2.656 & .110 & .058 \\
ESOL group (E) & 1 & .277 & .277 & .008 & .929 & $<.001$ \\
G×E & 1 & 144.270 & 144.270 & 4.155 & .046 & .065 \\
Error & 60 & 2083.497 & 34.725 & & & \\
$\quad$ Total & 64 & 4193.600 & & & & \\
\hline
\end{tabular}

\section{Results of testing research hypothesis five.}

Hypothesis \#5

There is a significant interaction between treatment and gender as reported by district records in determining the scores of EL students on an AAAS Physical Science 
comprehensive examination when these scores are adjusted for pre-treatment $A A A S$

scores.

Table 9 presents the descriptive statistics for participants' AAAS Physical Science examination pretest and posttest scores and their gender.

Table 9

Descriptive Statistics of the AAAS Physical Science Examination and Student Sex $(N=75)$

\begin{tabular}{|c|c|c|c|c|c|}
\hline \multirow[b]{2}{*}{ Group } & \multirow[b]{2}{*}{$n$} & \multicolumn{2}{|c|}{$\begin{array}{c}\text { Pretest } \\
\text { AAAS Science }\end{array}$} & \multicolumn{2}{|c|}{$\begin{array}{c}\text { Posttest } \\
\text { AAAS Science }\end{array}$} \\
\hline & & $M$ & $S D$ & $M$ & $S D$ \\
\hline $\begin{array}{l}\text { Academic conversation } \\
\text { (all participants) }\end{array}$ & 39 & 19.23 & 7.282 & 21.21 & 6.578 \\
\hline Males & 22 & 21.41 & 7.842 & 22.59 & 6.919 \\
\hline Females & 17 & 16.41 & 5.501 & 19.41 & 5.821 \\
\hline $\begin{array}{l}\text { Publisher materials (all } \\
\text { participants) }\end{array}$ & 36 & 22.50 & 7.970 & 23.44 & 9.581 \\
\hline Males & 21 & 25.33 & 8.434 & 27.24 & 9.088 \\
\hline Females & 15 & 18.53 & 5.317 & 18.13 & 7.726 \\
\hline
\end{tabular}

Table 10 is the source table for the analysis of covariance that was performed to test Hypothesis 5. No significant interaction was found between the treatment received by participants and their gender in determining the AAAS Science posttest scores $(p=.100)$. 
Table 10

Analysis of Covariance Using Gender and Instructional Method

With AAAS Physical Science Pretest Scores as Covariate

\begin{tabular}{lrrrrrr}
\hline \multicolumn{1}{c}{ Source } & $d f$ & \multicolumn{1}{c}{ SS } & \multicolumn{1}{c}{ MS } & \multicolumn{1}{c}{$F$} & \multicolumn{1}{c}{$p$} & \multicolumn{1}{c}{$\eta^{2}$} \\
\hline AAAS science pretest & 1 & 1375.139 & 1375.139 & 36.190 & $<.001$ & .341 \\
Group (G) & 1 & .602 & .602 & .016 & .900 & $<.001$ \\
Gender (S) & 1 & 96.636 & 96.636 & 2.543 & .115 & .035 \\
G $\times$ S & 1 & 105.442 & 105.442 & 2.775 & .100 & .038 \\
Error & 70 & 2659.840 & 34.725 & & & \\
$\quad$ Total & 74 & 4193.600 & 37.998 & & & \\
\hline
\end{tabular}

\section{Qualitative Results}

The researcher conducted observations of treatment group classes. Additionally, teachers responded to interview questions concerning demographics and perceptions of the treatment.

\section{Observations of treatment groups.}

The researcher conducted observations of the final summarization and discussion sessions of the two treatment groups during the $10^{\text {th }}$ week of implementation (see Appendix L). Both instructors' classes were observed on the same day.

Both teachers exhibited acceptable compliance to implementation guidelines.

They actively monitored student actions, observing that each was on task. Neither offered comment on individual summaries or group discussions. There were no instances requiring student redirection. Instructors did not interfere with student interaction. One action related to discipline occurred in one of the classrooms. The teacher reported that one student had a record of disruptive classroom behavior and noncompliance regarding academic activities. Therefore, based on prior conduct, he was isolated from the small 
groups prior to commencement of activities. No other significant factors, such as fire drills, emergency lockdowns, extended PA announcements, or interruptions by either administrators or school security occurred in either classroom.

\section{Teachers' educational background, training, and experience.}

Teachers responded to questions relative to demographic factors. Items related to educational background, training, and experience. (See Appendix M.)

Teacher 1 had 22 years of classroom experience in the district. She taught general education, secondary school science classes for 17 years. Prior to that, she had taught special education classes. She had been an instructor for grades six through 12 . Her teaching schedule for the year in which the investigation was conducted included all ninth-grade physical science classes.

She was not trained as a teacher, but had a background in science including a bachelor's degree in biology. She earned a master's degree in special education but did not participate in a teacher internship.

Teacher 2 had 21 years of classroom experience, including 13 years in general education science classes in the district. He had taught elementary school Grade 2 through Grade 5. As a secondary school science teacher, he had taught Grades 11 and 12. His teaching schedule for the year in which the investigation was implemented was comprised of exclusively ninth-grade physical science classes.

He was not trained as a secondary school science teacher but instead as an elementary school teacher. His bachelor's degree was in elementary education and he 
held a master's of science degree in science education. His teacher internship involved fourth-grade classes.

\section{Teachers' perceptions of the treatment.}

Teachers responded to questions on perceptions of the treatment. Items related to favorable and unfavorable aspects of the treatment and suggestions for improvement (See Appendix M)

Teacher 1 reported that some students exhibited focus and appeared to be putting forth effort. She maintained that time constraints inhibited student performance. She believed students' low academic level and English language proficiency combined to create a situation in which more time was required to achieve the objectives of the strategy.

She suggested that training in the strategy should occur during the first weeks of the school year. She held that greater benefit might be realized in this way.

Teacher 2 noted that the academic conversations discourse moves aided the students in the independent summarization of textbook readings. He too mentioned time constraints. He believed more time was required in order for effective discussion in small groups to occur.

He suggested implementing the treatment in a setting with fewer students, as opposed to a classroom of 25 or more. In addition, he recommended the use of adult coaches who could be utilized to model the strategy. 


\section{Summary}

No significant difference was found between the mean scores on the American Association for the Advancement of Science Physical Science posttest of treatment group and comparison group participants. Additionally, no significant interaction was found between the treatment received by participants and their FCAT 2.0 Science scores or their Florida Standards Assessment English Language Arts reading scores in determining the mean scores on the posttest. No significant interaction was found between the treatment received by participants and their gender, as reported by district records, in determining the mean scores on the AAAS Physical Science posttest. However, there was a significant interaction between treatment and level of English language proficiency, as measured by the Comprehensive English Language Learning Assessment (CELLA), in determining the mean scores of EL students on the posttest.

Observations of treatment groups showed no unacceptable departure from the guidelines by teachers. No disruption to the learning environment occurred. Teacher demographic data indicated that both had over two decades of district classroom experience. Both held master's degrees in education but neither had completed a teaching internship in science. Notable perceptions by teachers included the need for a longer duration for implementation and increased training in the strategy for students. 


\section{CHAPTER V}

\section{CONCLUSIONS}

The purpose of this study was to examine the effect of independent summarization of silently read state-adopted physical science textbook material in conjunction with student-led discussion in small groups, comprised of ninth-grade English Learners (ELs), on the comprehension of science text. The investigation also examined the effect of the treatment relative to students' background knowledge in science, reading level, degree of English language proficiency, and gender. This chapter will include a restatement the problem, summary of design and procedures, summary of findings, conclusions, implications, and suggestions for future research.

\section{Restatement of the Research Problem}

The White House, the U.S. Congress, state and local governments, and voters are inquiring as to possible means by which to increase the effectiveness of public education and thereby our students' academic development including their body of scientific knowledge (U.S. Department of Education, 2009; Alliance for Excellent Education, 2007). Reading scores of American students, particularly those of adolescents, in comparison with those of other countries have been an issue for decades (National Center for Educational Statistics, 2010). Expository text, encountered by secondary school students in content area classes, presents challenges different from those of narrative text (International Reading Association, 2006). The language of science in particular differs significantly from that of other fields of study (Fang, 2006). 
The development of science literacy in U.S. schools is also impacted by the pronounced increase in the number of EL Hispanic students in recent years (U.S. Census Bureau, 2012), who experience greater comprehension difficulties in science classes than their English speaking peers (Fang, 2006). Continued immigration has made for a situation in which the success of students who are English language learners is essential (National Assessment of Educational Progress, 2009). In order to acquire the requisite subject area knowledge, to earn credit in high school science courses, to succeed on statemandated science assessments, and thereby to graduate, ELs must have the ability to learn grade level science textbook content and to participate in conversations to build upon prior knowledge while concurrently developing content knowledge (Bunch. Kibler, \& Pimentel, 2012).

This present study examined the effect of student-led small group discussion on the comprehension of state-adopted science textbook readings by public high school students who are English Learners. Further, it analyzed its impact relative to prior science knowledge, reading level, English proficiency, and gender.

\section{Design and Procedures}

This investigation used both quantitative and qualitative methodology. Quantitative methods were used to measure the effect of independent written summarization of silently read, state-adopted physical science textbook material, in tandem with student-led small discussion of text and revision of summaries, on English Learners' comprehension of science text. Written summarization and small group 
discussion, it should be noted, employed the academic discourse moves developed by Zwiers and Crawford (2011).

Quantitative methodology was further utilized to analyze the impact of the treatment in conjunction with individuals' science background knowledge, reading level, English proficiency, and gender. One hundred three adolescent English Learners were enrolled in a district-required ninth-grade physical science high school class in a predominately Hispanic public school. Students were members of one of four active, day school classes taught by one of two state-certified secondary school science teachers. Each instructor had a treatment group and a comparison group. Prior to implementation, the researcher explained the study and presented the script to the teachers. Flash drives with the scripted lesson, student handouts outlining academic discourse moves (Zwiers \& Crawford, 2011) related to written summarization of text and oral discussion thereof, and student composition books were supplied. The flash drive included the script for the initial presentation of the strategy to students as well as the material for a brief review for the following treatment sessions as needed. It also contained a summary of small group procedures and strategy steps for display at each session to be utilized by teachers when necessary.

Preceding implementation, students sat for an American Association for the Advancement of Science (AAAS) Physical Science comprehensive examination (AAAS Test, 2015), made up of 53 multiple choice items, as a pretest. The next session involved the classroom teachers training the students in the strategy. This was followed by eight sessions in which students independently implemented the strategy. The final week 
students sat for the posttest. The entire implementation transpired during the course of normal school day operations.

Qualitative methods were used in the teacher interview process at the conclusion

of the study. The classroom instructors responded to questions concerning academic background, teacher training, and classroom experience as well as their perceptions of the treatment.

\section{Summary of Major Findings}

The initial analysis of data related to comparison of gains in test scores of the treatment group with those of the comparison group. This involved an analysis of covariance with the pretreatment $A A A S$ examination scores as the covariate, the posttreatment scores as the dependent variable, and the teaching method as the independent variable. This was tested at the alpha $=.05$ level of significance.

Analysis of pretest and posttest scores relative to students' science, reading, and English language proficiency levels as well as students' gender involved a factorial analysis of covariance. Pretreatment AAAS scores were the covariate, posttreatment AAAS scores were the dependent variable, teaching method and accordingly either eighth-grade FCAT 2.0 Science scores, eighth-grade Florida Standards Assessment English Language Arts reading scores, Comprehensive English Language Assessment scores, and gender were the independent variables. Interactions between the pair of independent variables in determining the dependent variable were tested at the alpha = .05 level of significance. 


\section{Quantitative findings.}

Hypothesis 1 stated that:

The mean test scores on an AAAS Physical Science comprehensive examination of ninth-grade ELs who participated in independent, written summarization of silently read science textbook material followed by student-led discussion in small groups, when adjusted for pre-treatment $A A A S$ scores, will be significantly higher than adjusted mean test scores of ninth-grade ELs who do not participate in the intervention.

The hypothesis was tested using an analysis of covariance with the pretreatment AAAS Physical Science comprehensive examination scores as the covariate, the posttreatment $A A A S$ Physical Science comprehensive examination scores as the

dependent variable, and teaching method as the independent variable. The hypothesis was tested at the alpha $=.05$ level of significance.

After participating in independent, written summarization of silently read science textbook material followed by student-led discussion in small groups, students did not significantly improve their comprehension of science text. No significant difference was found in the mean posttest scores of treatment group students and comparison group students.

Hypothesis 2 stated:

There is a significant interaction between treatment and level of prior science knowledge as measured by the eighth-grade FCAT 2.0 Science in determining the 
scores of EL students on an AAAS Physical Science comprehensive examination when these scores are adjusted for pre-treatment $A A A S$ scores.

The hypothesis was tested using a factorial analysis of covariance. The pretreatment AAAS Physical Science comprehensive examination scores were used as the covariate, the posttreatment AAAS Physical Science comprehensive examination scores were used as the dependent variable, and teaching method and level of prior science knowledge (measured by the eighth-grade FCAT 2.0 Science assessment) were the independent variables. The hypothesis for interaction between the independent variables in determining the dependent variable was tested at the alpha $=.05$ level of significance.

After participating in independent, written summarization of silently read science textbook material followed by student-led discussion in small groups, students did not significantly improve their comprehension of science text regardless of prior science knowledge. No significant difference was found in the mean posttest scores of treatment group students and comparison group students.

Hypothesis 3 stated:

There is a significant interaction between treatment and reading level as measured by the Florida Standards Assessments English Language Arts (FSA ELA) in determining the scores of EL students on an AAAS Physical Science comprehensive examination when these scores are adjusted for pre-treatment $A A A S$ scores. 
The hypothesis was tested using a factorial analysis of covariance. The pretreatment AAAS Physical Science comprehensive examination scores were used as the covariate, the posttreatment AAAS Physical Science comprehensive examination scores were used as the dependent variable, and teaching method and reading level (measured by the eighth-grade Florida Standards Assessments English Language Arts [FSA ELA]) were the independent variables. The hypothesis for interaction between the independent variables in determining the dependent variable was tested at the alpha $=.05$ level of significance.

After participating in independent, written summarization of silently read science textbook material followed by student-led discussion in small groups, students did not significantly improve their comprehension of science text regardless of reading level. No significant difference was found in the mean posttest scores of treatment group students and comparison group students.

Hypothesis 4 stated:

There is a significant interaction between treatment and level of English language proficiency as measured by the Comprehensive English Language Learning Assessment (CELLA) in determining the scores of EL students on an AAAS Physical Science comprehensive examination when these scores are adjusted for pre-treatment $A A A S$ scores.

It was tested using a factorial analysis of covariance. The pretreatment $A A A S$ Physical Science comprehensive examination scores were used as the covariate, the posttreatment AAAS Physical Science comprehensive examination scores were used as 
the dependent variable, and teaching method and level of English language proficiency (measured by the Comprehensive English Language Learning Assessment [CELLA]) were the independent variables. The hypothesis for interaction between the independent variables in determining the dependent variable was tested at the alpha $=.05$ level of significance.

After participating in independent, written summarization of silently read science textbook material followed by student-led discussion in small groups, students did not significantly improve their comprehension of science text regardless of level of English language proficiency. No significant difference was found in the mean posttest scores of treatment group students and comparison group students. This indicated a lack of effect on reading achievement regarding general ESOL level.

However, univariate analysis of variance showed a significant difference, 8.651 points, between the mean scores of high and low ESOL level comparison group students. Whereas, there was no significant difference, 1.990 points, between the mean scores of high and low ESOL level treatment group students. The lower English language proficiency treatment group students performed closer to the performance level of the higher English language proficiency treatment group students. This appears to indicate that the treatment had a positive impact on low ESOL level participants.

Hypothesis 5 stated:

There is a significant interaction between treatment and students' gender in determining the scores of EL students on an AAAS Physical Science 
comprehensive examination when these scores are adjusted for pre-treatment $A A A S$ scores.

The hypothesis was tested using a factorial analysis of covariance. The pretreatment AAAS Physical Science comprehensive examination scores were used as the covariate, the posttreatment AAAS Physical Science comprehensive examination scores were used as the dependent variable, and teaching method and student gender (as reported by district records) were the independent variables. The hypothesis for interaction between the independent variables in determining the dependent variable was tested at the alpha $=.05$ level of significance.

After participating in independent, written summarization of silently read science textbook material followed by student-led discussion in small groups, students did not significantly improve their comprehension of science text regardless of gender. No significant difference was found in the mean posttest scores of treatment group students and comparison group students.

\section{Qualitative findings.}

Both teachers had over two decades of experience in district classrooms and held advanced degrees in education. Both responded favorably to the treatment and noted that time constraints were a factor in implementation that may have had an impact on results.

\section{Discussion}

This exploratory study drew on research-based theory and practices to develop and assess a new strategy for enhancing the comprehension of science text by adolescent 
English language learners in public schools. The participants were high risk for numerous reasons including low socioeconomic status and frequent relocation. Little research exists to guide teachers or the developers of curriculum in helping such students to grasp concepts encountered in science classrooms while struggling to learn a new language. Numerous obstacles were overcome during the implementation of this preliminary research. Nonetheless, it has succeeded to an extent in adding to the body of research.

The purpose of this study was to examine the effect of independent summarization of silently read state-adopted physical science textbook material in conjunction with student-led discussion in small groups, comprised of ninth-grade English Learners (ELs), on the comprehension of science text. The investigation also examined the effect of the treatment relative to students' background knowledge in science, reading level, degree of English language proficiency, and gender.

The study sought to recruit classes with students who were a representative sample of Spanish-speaking English Learners in ninth-grade high school science classes in the Southeastern United States. However, internal validity may have been impacted by the differential selection of subjects. Selected groups may differ due to characteristics of members such as motivation, country of origin, and age. The external validity relative to populations other than Hispanic students may have been affected by cultural attitudes toward collaborative academic tasks. The results may not be applicable to other ethnic groups.

This study differed from prior research in several ways. The sample was comprised of students enrolled in a public high school in a large American school district. It took place in a predominantly Hispanic area. Reading materials were state-mandated 
textbooks. It transpired in a district-required course. The subject area was science, specifically physical science. The treatment was administered by the students' classroom teachers in the course of the normal school day. Pre- and posttests were utilized. The assessments were developed by the American Association for the Advancement of Science (AAAS, 2013).

The challenges presented by conducting field research in a public school, in a large urban school district, during the course of normal classroom operations, were many. Numerous limitations resulted. At the beginning of this investigation, the sample included 96 ninth-grade high school science students. Twenty students failed to sit for the posttest. The pre- and posttest scores of one student were discarded due to noncompliance during testing. At the completion of the study, the sample was comprised of 75 subjects. This number of participants was significantly lower than originally planned.

This study was implemented at a secondary school in an area with a high percentage of migrant workers. This can have an adverse effect on student attendance and transfer rates. Consequently, test scores for many group members were not available. In addition to posttest scores, this included eighth-grade FCAT 2.0 Science scores and eighth-grade Florida Standards Assessment English Language Arts scores. The amount of student data examined in regard to the five hypotheses was impacted. Available data varied for each participant. In spite of the awareness prior to the commencement of this investigation of the likelihood of such circumstances, the researcher proceeded in that the goal was to study this population.

Difficulties were experienced in finding a site for the investigation resulting in a delayed start of the study. In the present state-mandated assessment-driven public school 
environment, principals, concerned with school grades and teacher evaluations based on test performance, were reticent to allow classroom time to be used for implementation of strategies not customary in the science classroom. Teachers, likewise, are often not willing to allow alternative methods to be implemented in their classrooms. For this same reason, the district research review committee granted access to the school sites with the provision that the study concluded prior to the beginning of state testing, which was the second week of April. Due to this condition, the implementation period could not be extended to compensate for the delayed start. The result was that the length of time of treatment implementation was shorter than the planned 17-week duration. The actual length of implementation was 11 weeks. Additionally, available classroom treatment time was limited to less than one hour of the 90 -minute period, once a week, as opposed to a full hour, twice a week, as originally planned.

In the post-implementation interview, one of the teachers remarked that, in light of students' low academic levels and lack of English language proficiency, the limited time available for treatment may have adversely affected student performance. She also suggested that presenting the strategy to students earlier in the school year might enhance its effect. (Appendix M.)

The demands of state testing had an additional impact on the original plan for the study. Teacher training was limited to one-half hour rather than the intended two-hour session. A greater amount of time for interaction between researcher and teachers may have had an appreciable impact on teachers' ability to train students in the strategy. It may also have had an influence regarding teacher vision of the potential of the treatment and support thereof. 
As means of gaining teacher support of the intervention, a second instrument, a comprehensive physical science examination, developed by the textbook publisher, was to be employed as pre- and posttest. Time constraints disallowed its use.

Fidelity issues may involve both teachers and students. It is uncertain whether aspects of the treatment influenced teacher instruction of comparison group students. Classroom observations were not able to address the possibility of this occurrence in that comparison groups were not included. Likewise, it is beyond the parameters of this exploratory investigation to ascertain whether treatment group students shared aspects of the treatment with their comparison group peers.

This investigation addressed the development of literacy skills, related to both reading and writing, along with oral language ability in content area classes by adolescent English language learners in public schools. The specific goal of this treatment is to enhance comprehension of science text. The broader goals are to develop students' understanding of and ability to use the language of science along with the nurturing of students as independent learners. Rather than fostering a dependence on textbook support materials and teacher instruction, it seeks to launch adolescents into a world of critical thought, collaborative investigation, community, and therefore intellectual and social development. Furthermore, it aims to mitigate the effect of low English language proficiency on classroom learning.

The results of the study appear to indicate that the treatment had a positive effect on the performance of low level ESOL students in a low socioeconomic level community with a high percentage of migrant workers. Given the at-risk nature of this population, this in encouraging. Further, the basic premise of the treatment appears promising. 
Evidence collected pertaining to its effect relative to students' general ESOL level, prior science knowledge, reading level, and gender neither confirmed nor denied the viability of the strategy. Finally, the pursuit of improving the academic performance of this vulnerable population is a worthy endeavor and should be continued.

\section{Suggested Future Research}

In conducting this investigation, numerous questions have arisen that may lead to further study. Numerous factors could be modified:

1. The duration of the implementation can be extended.

2. The number of classroom observations can be increased and can include comparison groups.

3. A rubric can be utilized to evaluate and provide feedback on student independent and group summaries.

4. Academic conversations can be recorded. A rubric can be utilized to evaluate and provide feedback to small groups.

5. Students can be interviewed as to perceptions of the impact of the strategy on comprehension of science text. 


\section{References}

Abedi, J. (2002). Standardized achievement tests and English language learners:

Psychometric issues. Educational Assessment, (8)3, 231-257.

Allen, H., \& Park, S. (2011). Science education and ESL students. Science Scope, 35(3), 29-35.

Alliance for Excellent Education. (2003). Adolescents and literacy: Reading for the $21^{\text {st }}$

Century. Retrieved from http://www.all4ed.org/files/AdolescentsAndLiteracy.pdf

Alliance for Excellent Education. (2007). Literacy instruction in content areas:

Getting to the core of middle and high school improvement. Retrieved from http://www.all4ed.org/publication_materials/reports

Alliance for Excellent Education. (2008). Dropouts, diplomas, and dollars: US high schools and the nation's economy. Retrieved from http://www.all4ed.org/ publication_materials/ reports

Alliance for Excellent Education. (2010). The economic benefits of halving the dropout rate: A boon to business in the nation's largest metropolitan areas. Retrieved from http://www.all4ed.org/publication_materials/ reports

Almasi, J. F., \& Garas-York, K. (2009). Comprehension and discussion of text. In S. E. Israel \& G. G. Duffy (Eds.), Handbook of research in reading comprehension (pp. 470-493). New York, NY: Routledge.

Alvermann, D. E., Gillis, V. R., \& Phelps, S. F. (2013). Content area reading and literacy. Upper Saddle River, NJ: Pearson.

American Association for the Advancement of Science. (2013). Benchmarks for science literacy: Habits of mind, communication skills. In AAAS Project 2061. Retrieved from http://www.project2061.org/publications/ bsl/online/index.php

American Association for the Advancement of Science, Test. (2015). AAAS Project 2061 science assessment. Retrieved from http://assessment.aaas.org/ pages/home

American Association for the Advancement of Science, Assessment. (2016). AAAS science assessment beta. Retrieved from http://assessment.aaas.org/pages/ faq\#testing

American Association for the Advancement of Science, History. (2016). Mission and history. Retrieved from http://www.aaas.org/about/mission-and-history 
Artley, A. S. (1953). Oral language growth and reading ability. The Elementary School Journal, 53(6), 321-328.

Artley, A. S. (April, 1968). Are there any real differences between reading instruction in the elementary school and in the high school? Paper presented at the International Reading Association Conference, Boston.

Ary, D., Jacobs, L. C., \& Sorensen, C. (2010). Introduction to research in education. Belmont, CA: Wadsworth Cengage Learning.

Atwater, M. M. (2010). Multicultural education and curriculum materials. Science Activities, 47(4), 103-108.

Au, K. H., \& Raphael, T. E. (2000). Equity and literacy in the next millennium. Reading Research Quarterly, 35(1), 170-188.

August, D. (2002). Presentation at a meeting of the Los Angeles Unified School District, Commerce, CA

August, D., McCardle, P., \& Shanahan, T. (2014). Developing literacy in English language learners: Findings from a review of experimental research. School Psychology Review, 43(4), 490-498.

Baker, E. E. (1968). Preparing teachers for effective teaching of oral language. The National Council of Teachers of English. Retrieved from http://www.ncte.org/ library/NCTEFiles/Resources/Journals/EE/1968/EE1968-2Preparing.pdf

Barton, A. C. (2009). Sreyashi Jhumki Basu: Building a more equitable world through science education. Cultural Studies of Science Education, 4(2), 393-397.

Bennet. J., Hogarth, S., Lubben, F., Campbell, B., \& Robinson, A. (2010). Talking science: The research evidence on the use of small group discussions in science teaching. International Journal of Science Education, 32(1), 69-95.

Berkeley, (2016). Social constructivism. University of California in Berkeley graduate division. Retrieved from http://gsi.berkeley.edu/gsi-guide-contents/learningtheory-research/social-constructivism/

Biancarosa, G. (2005). After third grade. Educational Leadership, 63(2), 16-22.

Bogdan, R. C., \& Biklen, S. K. (2007). Qualitative research for education: An introduction to theories and methods. New York, NY: Allyn \& Bacon. 
Bridgeland, J. M., Dilulio, J. J., \& Morison, K. B. (2006). The silent epidemic (Civic Enterprises \& Peter D. Hart Research Associates for the Bill \& Melinda Gates Foundation). Retrieved from http://www.civicenterprises.net/ pdfs/thesilentepidemic3-06.pdf

Brown, A. L., \& Day, J. D. (1983). Macro-rules for summarizing texts: The development of expertise. Journal of Verbal Learning and Verbal Behavior, 22, 1-14.

Brown, B. A. (2005). The politics of public discourse: Discourse, identity, and AfricanAmericans in science education. Negro Educational Review, 56(2/3), 205-220.

Brown, B. A. (2011). Isn't that just good teaching? Disaggregate instruction and the language identity dilemma. Journal of Science Teacher Education, 22, 679-704.

Bunch, G. C., Kibler, A., \& Pimentel, S. (2012). Realizing opportunities for English Learners in Common Core English language arts and disciplinary literacy standards. Retrieved from http://ell.stanford.edu/sites/default/files/pdf/academicpapers/01_Bunch_Kibler_Pimentel_RealizingOpp\%20in\%20ELA_FINAL_0.pdf

Campbell, L., \& Campbell, B. (2009). The role of prior knowledge in learning. Retrieved from http://www.corwin.com/upm-data/25914_081222_ Campbell_Ch1_excerpt.pdf

Campbell, N. A., Williamson, B., \& Heyden, R. J. (2007). Biology: Exploring Life. Boston, MA: Pearson Prentice Hall.

CELLA ETS. (2005). CELLA technical summary report. Princeton, NJ: ETS.

Charles, C. M., \& Mertler, C. A. (2002). Introduction to educational research. Boston, MA: Allyn \& Bacon.

Chenoweth, G. (1969). The cultural bind on the American male. The National ACAC Journal, 14(2), 12-19.

Clark, P. J., Snowling, M. J., Truelove, E., \& Hulme, C. (2010). Ameliorating children's reading comprehension difficulties: A randomized controlled trial. Psychological Science, 21(8), 1106-1116.

Cloer, T., \& Pearman, B. (1993). The relationship of gender to attitudes about academic and recreational reading. American Reading Forum Online Yearbook: Reading Strategies, Practices, and Research for the $21^{\text {st }}$ Century, XIII. Retrieved from http://americanreadingforum.org/yearbook/yearbooks/93_yearbook/volume93toc. htm 
Common Core State Standards. (2013). English language arts standards: Science \& technical subjects, grades 9-10. Retrieved from http://www.corestandards.org/ ELA-Literacy/RST/9-10

Common Core State Standards Initiative. (2015). English language arts standards, standard 10: Range, quality, \& complexity, measuring text complexity, three factors. Retrieved from http://www.corestandards.org/ELA-Literacy/standard-10range-quality-complexity/measuring-text-complexity-three-factors/

Conley, M. (2009). Improving adolescent comprehension: Developing comprehension strategies in the content areas. In S. E. Israel \& G. G. Duffy (Eds.), Handbook of research on reading comprehension (pp. 531-550). New York, NY: Routledge.

Corder, G. (2007). Supporting English language learners. Science Scope. Retrieved from http://matkinsscienceeducation20042014.wmwikis.net/file/view/Readingsin ScienceMethodsbook.pdf\#page $=241$

Crawford-Brooke, E. (2013). The critical role of oral language for Title I students and English language learners. Retrieved from http://www.lexialearning.com/ effectiveness/whitepapers/oral-language-whitepaper

Cundiff, J. L., Vescio, T. K., Loken, E., \& Lo, L. (2013). Do gender-science stereotypes predict science identification and science career aspirations among undergraduate science majors? Social Psychology of Education, 16(4), 541-554.

Dillon, S. (2010, March 24). Reading scores lagging compared with math. The New York Times. Retrieved from http://www.nytimes.com/2010/03/25/Education/25reading. html

Duke, N. K. (2004). The case for informational text. Educational Leadership, 61(6), 40-44.

Ediger, M. (2002). Literacy and literature circles. Retrieved from Educational Full Text H. W. Wilson.

Fang, Z. (2006). The language demands of science in middle school. International Journal of Science Education, 28(5), 491-520.

FDOE, Bureau. (2014). Florida standards. Retrieved from http://www.fldoe.org/ bii/curriculum/sss/

FDOE, CELLA. (2014). Florida: Comprehensive English Language Learning Assessment. Retrieved from http://www.fldoe.org/aala/cella.asp 
FDOE, CELLA. (2015). CELLA. Retrieved from http://www.fldoe.org/academics/englanguage-learners/cella/

FDOE, Common Core. (2013). Countdown to Common Core. Retrieved from https://www.fldoe.org/schools/ccc.asp

FDOE, EOC. (2013). Florida end of year (EOC) assessments. Retrieved from http://fcat.fldoe.org/eoc/

FDOE, FCAT. (2013). FCAT 2.0: Florida statewide assessments 2013 technical report. Retrieved from http://www.fldoe.org/core/php/1314FAATechReport.pdf

FDOE, FCAT 2.0. (2013). FCAT 2.0: Florida statewide assessments 2013 yearbook.

Retrieved from http://www.fldoe.org/core/php/1314FAATechYearbook.pdf

FDOE, FSA. (2015). Florida Standards Assessment 2014-2015, Volume 4: Evidence of Reliability and Validity. Retrieved from http://www.fsassessments.org/wpcontent/uploads/2016/04/V4_FSA_TechRpt_508.pdf

FDOE, Results. (2015). Results 2014 Florida EOC assessments. Retrieved from http://www.fldoe.org/accountability/assessments/k-12-studentassessment/results/2014.stml

Federal Bureau of Prisons. (2013). Quick facts about the Bureau of Prisons: Inmate population and inmate breakdown. Retrieved from http://www.bop.gov/news/ quick.jsp

Feldon, D. F., Timmerman, B. C., Stowe, K. A., \& Showman, R. (2010). Translating expertise into effective instruction: The impact of Cognitive Task Analysis (CTA) on lab report quality and student retention in biology sciences. Journal of Research in Science Teaching, 47(10), 1165-1185.

Fine, J. C. (December, 2012). Students' comprehension of expository text: Teaching text structure, learning through discussion and written retellings. Paper presented at the annual conference of the American Reading Forum, Sanibel Island, FL.

Frank, B. N. (2011). Teaching science to English language learners: Instructional approaches of high school teachers. (Doctoral dissertation) Retrieved from ProQuest. (3495095)

Freire, P. (1998). Pedagogy of freedom: Ethics, democracy, and civic courage. Lanham, MD: Rowman and Littlefield. 
Gagnon, M. J., \& Abell, S. K. (2009). ELLs and the language of school science. Science and Children, 46(6), 50-51.

Gambrell, L. B. (December, 2012). The contribution of discussion to reading comprehension and critical thinking. Paper presented at the annual conference of the American Reading Forum, Sanibel Island, FL

Gay, G. (2009). Similar concerns, different perspectives of social studies and multicultural education. Social Studies Review, 48(1), 25-27.

Gersten, R., \& Baker, S. (2000). What we know about effective instruction for English language learners. Exceptional Children, 66(4), 454-470.

Geva, E., \& Massey-Garrison, A. (2012). A comparison of the language skills of ELLs and monolinguals who are poor decoders, poor comprehenders, or normal readers. Journal of Learning Disabilities, 46(5), 387-401.

Hadjar, A., Krolak-Schwerdt, S., Priem, K., \& Glock, S. (2014). Gender and educational achievement. Educational Research, 56(2), 117-125.

Halim, L., Samsudin, M. A., Subahan, T., Meeran, M., \& Osman, K. (2006). Measuring science teachers' stress level triggered by multiple stressful conditions. International Journal of Science and Mathematics Education, 4(4), 727-739.

Heineke, A. J. (2014). Dialoging about English learners: Preparing teachers through culturally relevant literature circles. Action in Teacher Education, 36(2), 117-140.

Hinkle, D. E., Wiersma, W., \& Jurs, S. G. (2003). Applied statistics for behavioral sciences. New York, NY: Houghton Mifflin.

Hoffman, J. V., (1979). The intra-act procedure for critical reading. Journal of Reading, 22, 605-608.

Hofstein, A., Navon, O., Kipnis, M., \& Mamlok-Naaman, R. (2005). Developing students' ability to ask more and better questions resulting from inquiry-type chemistry laboratories. Journal of Research in Science Teaching, 42(7), 791-806.

Hsu, T. C., Eddleman, S., Abel, M. B., \& Eldridge., P. (2011). Foundations of physical science. CPO Science: Nashua, NH.

International Reading Association. (2006). Standards for middle and high school literacy coaches. Newark, DE: Author.

Kent, A. M. (2004). Improving teacher quality through professional development. Education, 124(3), 427-435. 
Kidder, R. W. (1990, April 23). Should schools pay the price of prison? The Christian Science Monitor. Retrieved from http://www.csmonitor.com/1990/0423/dkid23. $\mathrm{html}$

Kim, W., \& Linan-Thompson, S. (2013). The effects of self-regulation on science vocabulary acquisition of English language learners with learning disabilities. Remedial and Special Education, 34(4) 225-236.

Kirkland, L. D., \& Patterson, J. (2005). Developing oral language in primary school classrooms. Early Childhood Education, 32(6), 391-395.

Klein, A. (2015). No Child Left Behind: An overview. Education Week. Retrieved from http://www.edweek.org/ew/section/multimedia/no-child-left-behind-overviewdefinition-summary.html

Klingner, J., Ahwee, S., Pilonieta, P., \& Menendez, R. (2003). Barriers and facilitators in scaling up research-based practices. Exceptional Children, 69(4), 411-429.

Lahelma, E. (2014). Troubling discourses on gender and education. Educational Research, 56(2), 171-183.

Larson, S. C. (2011). The effects of academic literacy instruction on engagement and conceptual understanding of biology ninth grade students. (Doctoral dissertation). Retrieved from ProQuest. (3455199)

Lee, O., Quinn, H., \& Valdes, G. (2013). Science and language for English language learners in relation to Next Generation Science Standards and with implications for Common Core Standards for English language arts and mathematics. Educational Researcher, (42)4, 223-233.

Lopez-Ferrao, J. E. (2008). Listening to middle school Spanish-speaking English language learners: A qualitative study of their perspectives on science. (Doctoral dissertation. Retrieved from ProQuest. (3340545)

Louis, R. A., \& Mistelle, J. M. (2012). The differences in scores and self-efficacy by student gender in mathematics and science. International Journal of Science and Mathematics Education, 10(5), 1163-1190.

Maloch, B. (2005). Moments by which change is made: A cross-case exploration of teacher mediation and student participation in literacy events. Journal of Literacy Research, 37(1), 95-142.

Miami-Dade County. (2009). Economic and Demographic Profile. Retrieved from http://www.miamidade.gov/oedit/library/10-10-economic_profile.pdf 
Miami-Dade County Public Schools. (2014). Assessment, Research, and Data Analysis. Retrieved from http://oada.dadeschools.net/TestingCalendar/TestingCalendar.asp

Miami-Dade County Public Schools, ESOL. (2015). English for Speakers of Other Languages (ESOL). Retrieved from http://ese.dadeschools.net/esol_ese/pdfs_ 11/lea-esol_guide_rev11.pdf

Miami-Dade County Public Schools, Learning. (2016). District Pacing Guide: Physical Science. Retrieved from https://village.dadeschools.net/lvcontentitems22/ lvcontentitems_22/dispform.aspx?id=28

Miller, C. C. (2010), April 17). Out of the loop in Silicon Valley. The New York Times. Retrieved from http://www.nytimes.com/2010/04/18/technology/18women.html? pagewanted=all\&_r=0

Moje, E. B., Ciechanowski, K. M., Kramer, K., Ellis, L., Carrillo, R., \& Collazo, T. (2004). Working toward third space in content area literacy: An examination of everyday funds of knowledge and discourse. Reading Research Quarterly, 39(1), 38-70.

Mueller, M., Tippins, D., \& Bryan, L. (2012). The future of citizen science. Democracy and Education, 20(1), 1-12.

National Assessment of Educational Progress. (2009). The nation's report card. Retrieved from http://nationsreportcard.gov/reading_2009/

National Center for Education Statistics, U.S. Department of Education. (2010). Highlights from PISA 2009: Performance of U.S. 15 year olds in reading, mathematics, and science literacy in an international context. Retrieved from http://nces.ed.gov/pubsearch/pubsinfo.asp?pubid=2011004

National Center for Educational Statistics, U.S. Department of Education. (2012). Fast Facts: Dropout rates. Retrieved from http://nces.ed.gov/fastfacts/display. asp?id=16

National Dropout Prevention Center, Clemson University. (2013). Top 5 reasons to stay in school. Retrieved from http://ndpc-web.clemson.edu/family-student-resources/

National Reading Panel. (2000). Teaching children to read: An evidence-based assessment of the scientific research literature on reading and its implications for reading instructi.on. Retrieved from http://www.nationalreadingpanel.org/ publications/publications.htm 
National Science Teachers' Association. (2003). NTSA position paper; Leadership in science education. Retrieved from http://www.nsta.org/about/positions/ leadership.aspx

National Science Teachers' Association, Guide. (2015). Guide to implementing Next Generation Science Standards. Retrieved from http://www.nextgenscience.org/ implementation

National Science Teachers' Association, Next. (2015). Next Generation Science Standards. Retrieved from http://standards.nsta.org/Standards/Display Standard.aspx? view=topic \&id=4

OADA. (2014). Florida CELLA fact sheet. Retrieved from http://oada.dadeschools. net/CELLA/cellainfosheet.pdf

Paris, S. G., \& Hamilton, E. E. (2009). The development of children's reading comprehension. In S. E. Israel \& G. G. Duffy (Eds.), Handbook of Research on Reading Comprehension (pp. 32-53). New York, NY: Routledge.

Pressley, M. (2000). What should comprehension instruction be the instruction of? In M. L. Kamil, P. B. Mosenthal, P. D. Pearson, \& R. Barr (Eds.) Handbook of reading research (pp. 545-561). Mahwah, NJ: Erlbaum.

Pressley, M. (2006). Reading instruction that works: The case for balanced teaching. New York, NY: Guilford.

Questar. (2014). Florida Comprehensive English Language Learning Assessment Technical Report Summary for the Spring 2014 Administration. Apple Valley, $\mathrm{MN}$ : Questar.

RAND Reading Study Group. (2002). Reading for understanding: Toward an $R \& D$ program in reading comprehension. Retrieved from http://www.rand.org/content/ dam/rand/pubs/monograph_reports/2005/MR1465.pdf

Raphael, T. E., \& Au, K. H. (2005). Enhancing comprehension and test taking skills across grades and content areas. The Reading Teacher, 59(3), 206-221.

Ravitch, D. (2010). The death and life of the great American school system: How testing and choice are undermining education. New York, NY: Basic Books.

Richardson, V. (2003). The dilemmas of professional development. Phi Delta Kappan, 84(5), 401-406. 
Rigdon, E. (1996). CFI versus RMSEA: A comparison of two fit indexes for structural equation modeling. Structural Equation Modeling: A Multidisciplinary Journal, 3(4), 369-379.

Rogevich, M. E., \& Perin, D. (2008). Effects on science summarization of a reading comprehension intervention for adolescents with behavior attention disorders. Exceptional Children, 74(2), 135-154.

Roseman, Stern, \& Koppal (2010). A method for analyzing the coherence of high school biology textbooks. Journal of Research in Science Teaching 47(1), 47-70.

Rubin, H. J., \& Rubin, I. S. (2012). Qualitative interviewing: The art of hearing data. Los Angeles, CA: Sage.

Ruddell, R. B., \& Unrau, N. J. (2004). Reading as a meaning-construction process: The reader, the text, and the teacher. In R. B. Ruddell \& N. J. Unrau (Eds.), Theoretical Models and Processes of Reading (pp. 1462-1521). Newark, DE: IRA.

Saleh, M., Lazonder, A. W., \& Jong, T. D. (2005). Effects of in-class ability grouping on social interaction, achievement, and motivation. Instructional Science, 33, 105119.

Schleppegrell, M.J. (2006). The challenges of academic language in school subjects. In I. Lindberg and K. Sandwall (Eds.), Språket och kunskapen: att lära på sitt andraspråk i skola och högskola (pp. 47-69). Göteborg, Sweden: Göteborgs universitet institutet för svenska som andraspråk. Retrieved April 14, 2008, from http://www.soe.umich. edu/events/als/downloads/schleppegrellp.html.

Scott, S., \& Palincsar, A. (2013). Sociocultural theory. Retrieved from http://www. education.com/reference/article/sociocultural-theory/

Shanahan, C. (2009). Disciplinary comprehension. In S. E. Israel \& G. G. Duffy (Eds.), Handbook of research on reading comprehension (pp. 240-260). New York, NY: Routledge.

Shanahan, T., \& Shanahan, C. (2012). What is disciplinary literacy and why does it matter? Topics in Language Disorders, 32(1), 7-18.

Shanahan T., \& Shanahan, C. (2008). Teaching disciplinary literacy to adolescents: rethinking content area literacy. Harvard Educational Review, 78(1), 40-59.

Shining Star. (2013) Differentiating language development in middle and high schools: Promoting oral language development and reading comprehension. Retrieved from http://static.dpsk12.org/gems/leadership/MSHSPromotingOralLanguage DevelopmentandReadingComprehension.pdf 
Sinnes, A., \& Loken, M. (2014). Gendered education in a gendered world: Looking beyond cosmetic solutions to gender gap in science. Cultural Studies of Science Education, 9(2), 343-364.

Smagorinsky, P. H. (2009). The culture of Vygotsky. Reading Research Quarterly, 44(1), 85-95.

Smith, C. (2003). The importance of expository text: Reading and Writing (TBC-03007). Washington, DC: Institute of Education Sciences.

Song, H. D., \& Grabowski, B. L. (2006). Stimulating intrinsic motivation for problem solving using goal-oriented contexts and peer group composition. Educational Technology: Research \& Development, 54(5), 445-466.

Soto-Hinman. (2011). Increasing academic oral language development using English language learner shadowing in the classroom. Multicultural Education, 18(2), 2023.

Sturtevant, E. G., \&Linek, W. M. (2003). The instructional beliefs and decisions of middle and secondary teachers who successfully blend literacy and content. Reading Research and Instruction, 43(1), 74-89.

Tobin, K. (2005). Building enacted science curriculum on the capital of learners. Science Education, 89(4), 577-594.

Tobin, K. (2006). Aligning the cultures of teaching and learning science in urban high schools. Cultural Studies in Science Education, 1(2), 219-252.

U.S. Census Bureau. (2012). Who's Hispanic in America? Retrieved from http://www.census.gov/newsroom/cspan/hispanic/2012.06.22_cspan_hispanics. pdf

U.S. Department of Education. (2016). NCLB: Reading First. Retrieved from http:// www2.ed.gov/programs/readingfirst/index.html

U.S. Department of Education. (2015). Developing Programs for English Language Learners: Lau v. Nichols. Retrieved from http://www2.ed.gov/about/offices/list /ocr/ ell/lau.html

Vacca, R. T., \& Vacca, J. L. (2008). Content area reading: Literacy and learning across the curriculum. Boston, MA: Pearson, Allyn, and Bacon.

Van den Branden, K. (2000). Does negotiation of meaning promote reading comprehension? A study of multilingual primary school classes. Reading Research Quarterly, 35(3), 426-443. 
Vernelson, S., \& Wilson, K. (2011). Research supporting strong oral language and vocabulary as major predictors of reading, literacy, and academic achievement. Retrieved from http://listeningandspokenlanguage.org/uploadedFiles/Connect/ Meetings/2012_Convention/Handouts/LanguageVersusAcademics_Handout.pdf

Vygotsky, L. S. (1978). Mind in Society. Mind in society: The development of higher psychological processes. Cambridge, MA: Harvard University Press.

Watts, R. (2014). Females in science: A contradictory concept? Educational Research, 56(2), 126-136.

WIDA. (2013). 2012 Amplification of the English Language Development Standards, Kindergarten-Grade 12. Retrieved from https://www.google.com/search? sourceid $=$ navclient $\&$ ie $=U T F-8 \& r l z=1 T 4 R V E B \_e n U S 606 U S 606 \& q=$ WIDA+science+standards

Wise, B. (2009). Adolescent literacy: The cornerstone of student success. Journal of Adolescent and Adult Literacy, 52(5), 369-375.

Wyss, V. L., Dolenc, N., Kong, X., \& Tai, R. H., 2013). Time on text and science achievement for high school biology students. American Secondary Education, 41(2), 49-59.

Zwiers, J., \& Crawford, M. (2011). Academic conversations: Classroom talk that fosters critical thinking and content understandings. Portland, ME: Stenhouse. 


\section{Appendix A}

\section{Observation Form}

[1] Teacher conforms to script:

[2] Teacher redirects students:

[3] Teacher refrains from participation in student discussion groups:

[4] Discipline incidents:

[5] Other factors: 


\section{Appendix $B$}

Teacher Interview Questions:

Educational Background, Training, Experience and Perceptions of Intervention

\section{Part I}

[1] How long have you been a classroom teacher?

[2] How long have you taught general education MDCPS science classes?

[3] What grades have you taught?

[4] Were you trained as a secondary school science teacher?

[5] In what area is your bachelor's degree?

[6] Do you have an advanced degree?

[7] Did you complete a teacher internship?

\section{Part II}

[1] What do you feel went well?

[2] What do you feel did not go well?

[3] Can you suggest a means by which the intervention could be improved? 
Student Handout I: Silent Reading and Summarization of Readings in Composition Book

\section{Silent Reading and Summarization: Academic Conversations Discourse Moves}

\begin{tabular}{|l|l|}
\hline \multicolumn{1}{|c|}{ Conversation Skills } & \multicolumn{1}{c|}{ How to Respond to the Text } \\
\hline Elaborate and clarify ideas & $\begin{array}{l}\text { I think it means... } \\
\text { In other words... } \\
\text { I believe that... } \\
\text { It is important because... } \\
\text { It is similar to when... }\end{array}$ \\
\hline Support ideas with evidence & $\begin{array}{l}\text { In the text it said that... } \\
\text { An example from my life is... } \\
\text { An illustration of this could be... }\end{array}$ \\
\hline Build on ideas & $\begin{array}{l}\text { I would add that... } \\
\text { Another way to look at this could be... } \\
\text { Yet I wonder if... }\end{array}$ \\
\hline Paraphrase & $\begin{array}{l}\text { So, the book is saying that... } \\
\text { In a nutshell, the book is saying that... } \\
\text { In other words... } \\
\text { Essentially, the book says that... } \\
\text { It sounds the book is saying that... }\end{array}$ \\
\hline Synthesize points & $\begin{array}{l}\text { We can say that... } \\
\text { The main point seems to be.... } \\
\text { The evidence seems to suggest that... }\end{array}$ \\
\hline
\end{tabular}




\section{Appendix D}

Student Handout II: Small Group Discussion

\section{Small Group Discussion: Academic Conversations Discourse Moves}

\begin{tabular}{|l|l|l|}
\hline Conversation Skills & $\begin{array}{l}\text { How to Ask Partners for } \\
\text { More Information on Ideas }\end{array}$ & $\begin{array}{l}\text { How to Respond to } \\
\text { Partners' Questions }\end{array}$ \\
\hline $\begin{array}{l}\text { Elaborate and clarify } \\
\text { ideas }\end{array}$ & $\begin{array}{l}\text { What do you mean by...? } \\
\text { Can you tell me more about? } \\
\text { What makes you think that? } \\
\text { How/why is that important? } \\
\text { I am a little confused about the } \\
\text { part... }\end{array}$ & $\begin{array}{l}\text { I think it means... } \\
\text { In other words... } \\
\text { I believe that... } \\
\text { It is important because... } \\
\text { It is similar to when... }\end{array}$ \\
\hline $\begin{array}{l}\text { Support ideas with } \\
\text { evidence }\end{array}$ & $\begin{array}{l}\text { Can you give me an example } \\
\text { from the text? } \\
\text { What is a real-world example? } \\
\text { Why do you say that? }\end{array}$ & $\begin{array}{l}\text { In the text it said that... } \\
\text { An example from my life } \\
\text { is... } \\
\text { An illustration of this } \\
\text { could be... }\end{array}$ \\
\hline $\begin{array}{l}\text { Build on or challenge } \\
\text { partners' ideas }\end{array}$ & $\begin{array}{l}\text { Can you add to this idea? } \\
\text { What might be some other } \\
\text { points of view? } \\
\text { How does that connect to the } \\
\text { other idea that...? }\end{array}$ & $\begin{array}{l}\text { I would add that... } \\
\text { Another way to look at } \\
\text { this could be... } \\
\text { Yet I wonder if... }\end{array}$ \\
\hline $\begin{array}{l}\text { I can't remember all that was } \\
\text { said. } \\
\text { How can we relate what I (or he } \\
\text { or she) said to the topic? } \\
\text { What do we know so far? } \\
\text { What is your take on what I } \\
\text { said? }\end{array}$ & $\begin{array}{l}\text { So, you are saying that... } \\
\text { In a nutshell, you are } \\
\text { saying that... } \\
\text { In other words... } \\
\text { Essentially, you think } \\
\text { that... } \\
\text { It sounds like you are } \\
\text { saying that... }\end{array}$ \\
\hline $\begin{array}{l}\text { How should we synthesize what } \\
\text { we talked about? } \\
\text { How can we bring this all } \\
\text { together? } \\
\text { What can we agree upon? } \\
\text { What main points can we share? } \\
\text { What key idea can we take } \\
\text { away? }\end{array}$ & $\begin{array}{l}\text { Whe main point seems to } \\
\text { be... } \\
\text { The evidence seems to } \\
\text { suggest that... }\end{array}$ \\
\hline
\end{tabular}


Appendix E

Relationship between CCSS and the Treatment: Examples Based on Sample Lesson Material from Appendix $G$

\begin{tabular}{|c|c|}
\hline Standards & Example from the Treatment Lesson \\
\hline $\begin{array}{l}\text { CCSS.ELA-Literacy.RST.9-10.1: } \\
\text { Cite specific textual evidence to } \\
\text { support analysis of science and } \\
\text { technical texts, attending to the } \\
\text { precise details of explanations and } \\
\text { descriptions. }\end{array}$ & $\begin{array}{l}\text { Using the Support Ideas with Evidence } \\
\text { skill, a student could select the "in the } \\
\text { text it said" discourse move. One could } \\
\text { write, "Freefall does not happen only } \\
\text { with falling objects. In the text it said } \\
\text { that "even going up, the ball is in free fall } \\
\text { because gravity is the only significant } \\
\text { force acting on it.", }\end{array}$ \\
\hline $\begin{array}{l}\text { CCSS.ELA-Literacy.RST.9-10.2: } \\
\text { Determine the central ideas or } \\
\text { conclusions of a text; trace the } \\
\text { text's explanation or depictions of a } \\
\text { complex process, phenomenon, or } \\
\text { concept, provide an accurate } \\
\text { summary of the text. }\end{array}$ & $\begin{array}{l}\text { Using the Synthesize Points skill, based } \\
\text { on his or her summary, a student could } \\
\text { select the "main point seems to be" } \\
\text { discourse move. One could write, "The } \\
\text { main point seems to be that free fall } \\
\text { involves acceleration due to gravitational } \\
\text { attraction." }\end{array}$ \\
\hline $\begin{array}{l}\text { CCSS.ELA-Literacy.RST.9-10.4: } \\
\text { Determine the meaning of symbols, } \\
\text { key terms, and other domain- } \\
\text { specific words and phrases as they } \\
\text { are used in a specific scientific or } \\
\text { technical context relevant to grades } \\
9 \text { and } 10 \text { texts and topics. }\end{array}$ & $\begin{array}{l}\text { Using the Elaborate and Clarify Ideas } \\
\text { skill, a student could select the "in other } \\
\text { words" discourse move. One could write, } \\
\text { "In other words, in physical science the } \\
\text { symbol } g \text { means } 9.8 \mathrm{~m} / \mathrm{s}^{2} . " \\
\text { Using the Build on Ideas skill, a student } \\
\text { could select the "yet I wonder if" } \\
\text { discourse move. One could write, "Yet I } \\
\text { wonder if scientists should change the } \\
\text { name of the term 'free fall' to something } \\
\text { like 'gravity acceleration' since objects } \\
\text { that are thrown upward are said to be in } \\
\text { free fall, even though they are not } \\
\text { falling, just because gravity is } \\
\text { accelerating them." }\end{array}$ \\
\hline
\end{tabular}




\begin{tabular}{|c|c|}
\hline $\begin{array}{l}\text { CCSS.ELA-Literacy.RST.9-10.5: } \\
\text { Analyze the structure of } \\
\text { relationships among concepts in a } \\
\text { text, including relationships among } \\
\text { key terms. }\end{array}$ & $\begin{array}{l}\text { Using the Paraphrase skill, a student } \\
\text { could select the "essentially the book } \\
\text { says" discourse move. One could write, } \\
\text { "Essentially the book says that both } 9.8 \\
\mathrm{~m} / \mathrm{s} \text { every second and } 9.8 \mathrm{~m} / \mathrm{s}^{2} \text { equal } \\
\text { acceleration due to gravity." }\end{array}$ \\
\hline $\begin{array}{l}\text { CCSS.ELA-Literacy.RST.9-10.9: } \\
\text { Compare and contrast findings } \\
\text { presented in a text to those from } \\
\text { other sources (including their own } \\
\text { experiments), noting when the } \\
\text { findings support or contradict } \\
\text { previous explanations or accounts. }\end{array}$ & $\begin{array}{l}\text { Using the Support Ideas with Evidence } \\
\text { skill, a student could select the "an } \\
\text { example from my life" discourse move. } \\
\text { One could write, "The book says that } \\
\text { when you throw a ball up in the air, it is } \\
\text { in free fall because gravity is the main } \\
\text { force on it. An example from my life is } \\
\text { when you bounce on a diving board. } \\
\text { Even when you jump up in the air, } \\
\text { before you start to drop into the water, } \\
\text { you are in free fall because gravity is the } \\
\text { main force acting on you." }\end{array}$ \\
\hline $\begin{array}{l}\text { CCSS.ELA-Literacy.RST.9-10.10: } \\
\text { By the end of grade } 10, \text { read and } \\
\text { comprehend science/technical texts } \\
\text { in the grades } 9 \text { and } 10 \text { text } \\
\text { complexity band independently and } \\
\text { proficiently. }\end{array}$ & $\begin{array}{l}\text { (See the CCSS Initiative text complexity } \\
\text { model in Appendix F.) Using the Support } \\
\text { Ideas with Evidence skill, a student } \\
\text { could select the "in the text it said" } \\
\text { discourse move. One could write, "In the } \\
\text { text it said that 'constant acceleration } \\
\text { means an object's speed changes by the } \\
\text { same amount each second.' This is hard } \\
\text { to understand but it makes sense if you } \\
\text { look at the diagram on page } 96 \text { of the } \\
\text { person dropping the ball off of the cliff." }\end{array}$ \\
\hline
\end{tabular}




\section{Appendix $F$}

\section{Common Core State Standards Text Complexity}

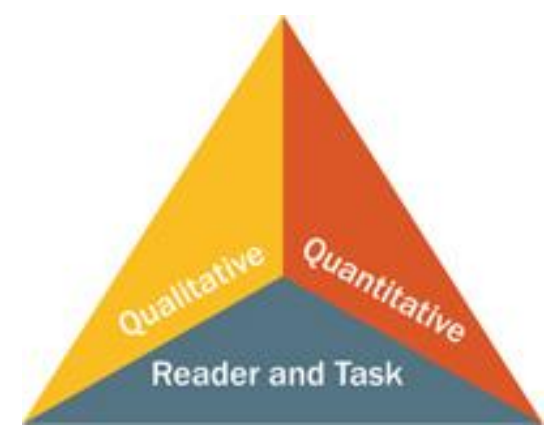

The Common Core State Standards Initiative (2015) defines text complexity via a three-part model comprised of the reader and task, qualitative, and quantitative dimensions. The reader and task dimension relates to motivation, prior knowledge, and purpose. The qualitative dimension relates to meaning, clarity, and language conventionality. The quantitative dimension relates to text cohesion, word frequency, word length, and sentence length. One factor considered by this latter dimension is that text complexity can be affected by the use of familiar language to communicate challenging concepts. 


\section{Appendix $G$}

\section{Teacher Training Script}

Introduction

Interaction began with thoughts on teaching, shop talk as it were. Its purpose was to decrease any possible ill at ease feelings and to initiate a working relationship. Teachers were encouraged to ask questions and comment throughout the training.

The title of the dissertation is Meaning Negotiated through Independently-Written Summaries and Oral Academic Conversations: Enhancing the Comprehension of Science Text by Ninth-Grade English Learners. Its aim is to test an intervention designed to, as the title suggests, increase students' ability to understand science textbooks by discussion readings. The ultimate goal is to increase student scores in end of course assessments in science and thereby contribute to an increase in graduation rates, teacher evaluation scores, and school grades.

Needless to say, in order for findings to be accurate, it is critical that scripts be faithfully followed. As teachers, we are accustomed to this through proctoring the FCAT and EOCs.

Prior to instruction, each student will be given a notebook with an attached twopart handout containing an explanation of academic conversations discourse moves by Zwiers and Crawford (2011) to be used for summarization and for discussion (see Appendices $\mathrm{G}$ and $\mathrm{H}$ ). 


\section{Teacher Script}

"Today we're going to work on a method of understanding science textbooks by first summarizing and then discussing in small groups what you think the chapter means. Let me show you the way to do summaries of paragraphs using the charts in your notebook. This is an Internet article, needless to say". [Display the photo below on the Promethean board.]

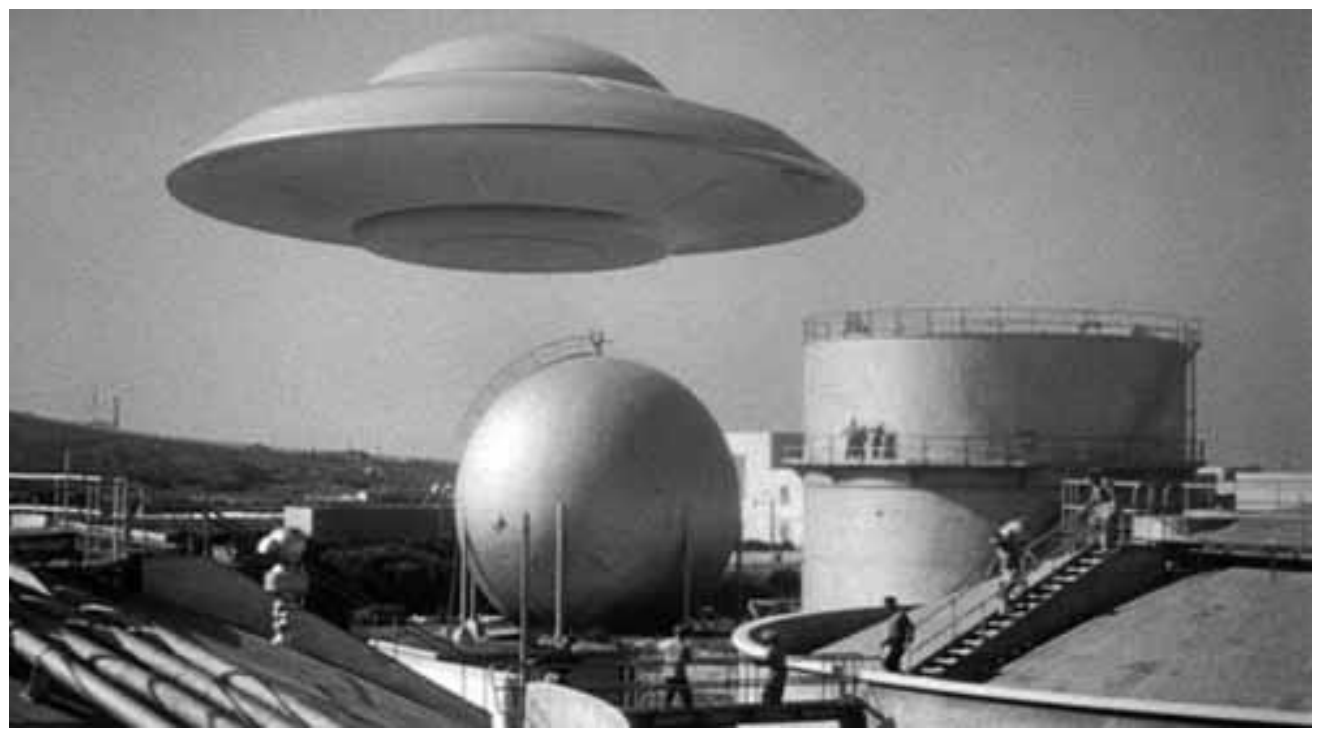

Display the article.

"The title is UFO Sightings News: New Year's Eve UFO Sightings Were Sky Lanterns, Says Orangeville Woman, As New Sightings Reported. It was written by someone named Tony Sokol and was published on January 20, 2014 at 2:52 pm EST."

Read:

UFO Sightings News: California is being hit with a rash of UFO reports. On Jan. 10, an eyewitness submitted a report to the Mutual UFO Network about strange lights that were visible just below the moon. The UFO was initially thought to be a star.

A man out with his daughter saw two lights appear below the moon that he now believes are UFOs. At first the father thought it was a star. He said "I was noticing what appeared to be two stars below the moon. I then noticed that the lower star started 
moving left to right and quickly noticed another star-like light below it suddenly appear and seem to be moving in unison." His daughter agreed saying "What the heck was that, that wasn't normal, did we just see UFOs?"

There were multiple sightings of UFOs over California on New Year's Eve. UFO sightings were reported all across California on New Year's morning. Some people thought the annual fireworks display was a little too out of this world and there were multiple UFO reports across the state. A woman from Orangeville says she may have the answers behind the mystery. Cathy Adams said she reviewed Internet and news reports of the California UFOs and did a little research. She concluded that the UFOs that people saw all over the state on New Year's were actually sky lanterns.

Adams says "I actually found it New Year's morning and I didn't know what it was. I have never seen anything like it before."

Adams said she doesn't know who released the sky lanterns, but she warns it could be a fire danger especially during this dry winter season. The lanterns require flames to produce the energy needed to take off. She said "They are always telling us on the news that wildfire can start with a simple spark, then why are we having these things fly around in the sky."

Witnesses say the lights over California wasn't fireworks, but a UFO.

The UFO sightings weren't just isolated to California. UFO sightings were also reported in North Carolina. Federal authorities said there has been no "unusual flight activity" in California.

Witnesses say that they saw four to six "unusual-looking" lights. California UFO sightings were reported all across California, including Stockton, Sacramento, and Auburn. The reports came few days after the discovery of a crop circle in Salinas, California.

Kaye Pinlac of Stockton told ABC News affiliate News 10 "I seen like six bright orange colored lights. They were almost like in a diamond or triangle shape. It was weird. And so they started just separating."

Pinlac said he caught the lights on a video on his phone.

Steven Brown told ABC News that he saw the same lights in Sacramento, "Well, we saw it right through the trees. It was bright enough to shine directly through the trees without any problem seeing it. Whatever it was moved up and to the left... It hovered there for probably about 60 seconds, then it took off at a high rate of speed."

Federal Aviation Administration spokesman Ian Gregor claims no UFO sightings were reported, "There was no unusual flight activity reported Tuesday night." 
Terry and Hans Mauth told News 10 they saw the same thing over Auburn. Mauth said "No sound, no blinking lights, just this big illuminated form."

A 2008 UFO sighting over the Sacrament Valley was revealed to be an airplane with an electric sign under the wings.

[End of article]

"When you summarize a passage, look at the discourse moves in the Silent Reading and Summarizing handout (see Appendix C). There are five conversation skills in the first column. In the second column, there are phrases you can use to guide your summary. Choose at least one phrase from each skill category to use in your summary.

"I will reread the first section of the article and demonstrate how to use this method."

Read:

UFO Sightings News: California is being hit with a rash of UFO reports. On Jan. 10, an eyewitness submitted a report to the Mutual UFO Network about strange lights that were visible just below the moon. The UFO was initially thought to be a star.

A man out with his daughter saw two lights appear below the moon that he now believes are UFOs. At first the father thought it was a star. He said "I was noticing what appeared to be two stars below the moon. I then noticed that the lower star started moving left to right and quickly noticed another star-like light below it suddenly appear and seem to be moving in unison." His daughter agreed saying "What the heck was that, that wasn't normal, did we just see UFOs?"

"For the Elaborate and Clarify skill, I am going to choose the phrase 'I believe that...' So I would begin the summary by writing, 'I believe that people saw lights that they thought were stars at first but then thought they were UFOs."”

"For the Support Ideas with Evidence skill, I am going to choose the phrase, 'In the text it said that...' So I would write, 'In the text it said that strange lights were visible by the Moon."”

"For the Build on Ideas, I am going to choose the phrase, 'I wonder if...' So I would write, 'I wonder if the people saw satellites reflecting the sun?'”

"For the Paraphrase skill, I am going to choose the phrase, 'In a nutshell the article is saying...' First, let me explain that expression. 'In a nutshell' means that you are going to explain in very few words. A nutshell is very small and cannot fit much. So I would write, 'In a nutshell, lights were believed to be UFOs."' 
"For the Synthesize Points skill, I am going to choose the phrase, 'The main point seems to be...' So I would write, 'The main point seems to be people saw lights in the sky that they could not identify."'

"Remember, the discourse moves are not always one-size-fits-all. You need to choose the one that fits best."

"Now let's use the method with the science textbook.

First, I will summarize the passage using discourse moves from the Summarizing handout (Appendix $C$ ). Then let's use discourse moves from the Group handout (Appendix D) to develop a discussion as you would in a small group.

"I will read the passage. I will summarize by using each of the five Conversation Skills categories. I will choose a How to Respond to the Text phrase for each one of the categories. After each response to the text that I give you, please look at the Group handout. Choose a How to Ask Partners for More Information on Ideas phrase from the middle column. Raise your hand. I will respond to you using a How to Respond to Partners' Questions phrase that I will choose from the last column."

"Please turn to page 96."

[NOTE: In that the study will commence following the ninth week of school, as previously explained. Passages used in training will be selected from chapters previously studied.]

Read:

"An object is in free fall if it is accelerating due to the force of gravity and no other forces are acting on it. A dropped ball is almost in free fall from the instant it leaves your hand until it reaches the ground. The 'almost' is because there is a little bit of air friction that does make an additional force on the ball. A ball thrown upward is also in free fall after it leaves your hand. Even going up, the ball is in free fall because gravity is the only significant force acting on it.

"If air friction is ignored, objects in free fall on Earth accelerate downward, increasing their speed by $9.8 \mathrm{~m} / \mathrm{s}$ every second. The value $9.8 \mathrm{~m} / \mathrm{s}^{2}$ is called the acceleration due to gravity. The small letter $g$ is used to represent its value. When you see the lowercase letter $g$ in a physics question, you can substitute the value $9.8 \mathrm{~m} / \mathrm{s}^{2}$ (Hsu, p. 96)." 
"If I were the first person to speak in the small group, the one beginning the conversation, I would choose to use an Elaborate and Clarify discourse move. I would choose the phrase 'I believe that...' So I would begin the discussion with, 'I believe that free fall is not only with falling objects."”

"Please choose a phrase from the How to Ask Partners column and raise your hand."

"For the Support Ideas with Evidence skill, I am going to choose the phrase, 'An illustration of this could be...' So I would say, 'An illustration of this could be when a skater jumps a ramp."”

"Please choose a phrase and raise your hand."

"For the Build on Ideas, I am going to choose the phrase, 'Another way to look at this could be..." So I would say, "Another way to look at this could be gravity is the main force a something in free fall."'

"Please choose a phrase and raise your hand."

"For the Paraphrase skill, I am going to choose the phrase, 'It sounds like the book is saying that...' So I would say, 'It sounds like the book is saying that if you do not count the force produced by the air, something that is in free fall will drop at 9.8 meters per second, each and every second."

"Please choose a phrase and raise your hand."

"For the Synthesize Conversation Points skill, I am going to choose the phrase, 'The main point seems to be...' So I say, 'The main point seems to be that free fall is caused by gravity alone and that objects will accelerate at the same rate."”

"Please choose a phrase and raise your hand."

"Now you try the method. Use the Silent Reading and Summary handout to summarize pages 108 through 110. Let's take 15 minutes to do this."

When students have finished the summaries: 
"I will assign you to small groups. I will appoint a leader. He or she is not the group dictator. The responsibilities are to keep students on task and to make sure that each student presents at least one How to Respond to the Text and at least one How to Ask Partners for More Information discourse move.

"After a person presents the response to the text from the Summarizing handout, the leader will ask another student to respond to the speaker using a How to Ask Partners for More Information discourse move from the Group handout. That first speak will then answer that question by selecting a How to Respond to Partners' Questions discourse move from the Group handout."

"You are free to respectfully agree or disagree based on your own written response or new opinion."

"When the discussion is complete, each person should revise his or her summary where it is needed."

Project and read the guidelines:

- Group size: 4 to 5 students.

- Students bring notebook with independently composed passage summaries to the discussion group.

- One student will preside, not dominate.

- Ground rules: Respect other people's ideas. All questions and comments are legitimate and necessary. The purpose is not to win an argument but instead to share ideas and to together interpret the textbook readings.

- Initially, each student in turn will give his or her response to a different section of a passage. Group members will in turn ask for more info. Peers will be permitted to contribute their perspectives.

- When a consensus (group agreement) is reached, each member will revise his or her summary for a particular paragraph in his or her notebook as need be. If there are dissenting opinions (opinions different than the majority), dissenters will be permitted to instead record an alternate interpretation.

- Presiding student responsibilities:

a. To ensure that the student given the floor is permitted to communicate his or her thoughts in an environment free of hostility

b. To ensure that each student has a chance to respond to the text and to ask partners for more info

c. To ensure that individuals do not dominate the discussion

d. To prevent excessive time from being spent on any one section 
e. To keep students on task.

f. Note: The presiding student is not the final judge on the validity of an interpretation.

Display on screen:

- By yourself, read the chapter in the book.

- When you finish reading a paragraph, write a short summary using the summarizing handout.

- In your small group (which I will organize), using the discussion handout, each person will share his or her response to a section of a passage. Each person will be given the chance to ask a speaker for more info. The group will discuss the ideas. People will share their thoughts based on their summaries. Together all group members will decide what the final version of each paragraph summary should include.

- Each member will submit his or her notebook containing the revised summary.

Note: Use the script for review and display student guidelines relative to the strategy and small groups in later sessions as necessary.

The following information was provided to the teachers:

Source for high interest article: http://www.kpopstarz.com/articles/74944/20140120/ufosightings-news-new-years-eve-sky-lanterns-orangeville-woman.htm

Source for science text: Hsu, Eddleman, Abel, and Eldridge (2011). Passages from Foundations of Physical Science, chapter 4, Motion 
[Note: Appendix E contains a chart which shows the relationship between Common Core State Standards in English language arts and literacy, pertaining to science and technical subjects, to the treatment.] 


\section{Appendix $H$}

Implementation Schedule

\begin{tabular}{|c|l|}
\hline \multicolumn{1}{|c|}{ Session } & Activities of Experimental Group Students, Teachers, Researcher \\
\hline Prior to treatment & Teacher training \\
\hline 1 & AAAS pretest \\
\hline 2 & Student training: instruction and practice \\
\hline 3 & Text reading, summarization, and discussion \\
\hline 4 & Text reading, summarization, and discussion \\
\hline 5 & Text reading, summarization, and discussion \\
\hline 6 & Text reading, summarization, and discussion \\
\hline 7 & Text reading, summarization, and discussion \\
\hline 8 & Text reading, summarization, and discussion \\
\hline 9 & Text reading, summarization, and discussion \\
\hline 10 & $\begin{array}{l}\text { Text reading, summarization, and discussion } \\
\text { Observation } \\
\text { Interview }\end{array}$ \\
\hline 11 & AAAS posttest \\
\hline
\end{tabular}




\section{Appendix I}

Specific Activities, General Activities, and General Lesson Plan Format Treatment and Comparison Groups

Specific Activities: Treatment and Comparison Groups

Treatment Group

\begin{tabular}{|c|c|}
\hline AAAS assessment: pretest & AAAS assessment: pretest \\
\hline $\begin{array}{l}\text { Independent textbook reading, } \\
\text { independent summarization of text, } \\
\text { small group discussion, } \\
\text { revision of text summary, } \\
\text { lecture, lab }\end{array}$ & $\begin{array}{l}\text { Independent textbook } \\
\text { reading, } \\
\text { copy textbook vocabulary, } \\
\text { complete textbook questions, } \\
\text { complete publisher handouts, } \\
\text { publisher workbook, } \\
\text { lecture, lab }\end{array}$ \\
\hline Silent textbook reading & Silent textbook reading \\
\hline Compose independent summaries & Copy textbook vocabulary \\
\hline Compose independent summaries & Complete textbook questions \\
\hline Discussion group & Complete publisher handouts \\
\hline Revision of summary & Publisher workbook \\
\hline Lecture & Lecture \\
\hline AAAS assessment: posttest & AAAS assessment: posttest \\
\hline $\begin{array}{l}\text { Compare FCAT } 2.0 \text { Science and posttest scores } \\
\text { Compare FSA ELA reading and posttest scores } \\
\text { Compare CELLA levels and posttest scores } \\
\text { Compare posttest scores based on gender }\end{array}$ & $\begin{array}{l}\text { Compare FCAT } 2.0 \text { Science } \\
\text { and posttest scores } \\
\text { Compare FSA ELA reading } \\
\text { and posttest scores } \\
\text { Compare CELLA levels and } \\
\text { posttest scores } \\
\text { Compare posttest scores } \\
\text { based on gender }\end{array}$ \\
\hline \multicolumn{2}{|l|}{ Teacher observations } \\
\hline $\begin{array}{l}\text { Teacher interview:, education, training, classroom } \\
\text { experience, and perceptions of intervention }\end{array}$ & \\
\hline
\end{tabular}




\section{General Activities, Treatment and Comparison Groups}

Treatment Group

Training in strategy for summarization employing the

Zwiers and Crawford (2011) discourse moves, as part

of standards-based science class instruction
Comparison Group Standards-based science class instruction sans student-led discussion groups and summarization

Standards-based science class instruction sans student-led discussion groups and summarization

Standards-based science class instruction sans student-led discussion groups and summarization 
General Lesson Plan Format, Treatment and Comparison Groups

Treatment Group

Teacher will briefly review summarization and discussion strategies (Zwier \& Crawford, 2011) as well as discussion ground rules and group leader responsibilities.

Independent reading as per CCSS using the summarization strategy:

Hsu, Eddleman, Abel, \& Eldridge Foundations of Physical Science textbook chapter.

Time: 30 minutes Comparison Group Independent reading as per CCSS: Hsu, Eddleman, Abel, \& Eldridge Foundations of Physical Science textbook chapter.

\begin{tabular}{|r|l|} 
Time: 30 minutes & Time: 20 minutes \\
\hline $\begin{array}{l}\text { Students discuss summaries and work } \\
\text { toward consensus on chapter meaning. }\end{array}$ & $\begin{array}{l}\text { Students use glossary to define vocabulary, } \\
\text { complete publisher workbook material, } \\
\text { publisher handouts, or textbook questions. }\end{array}$ \\
Time: 20 minutes & Time: 30 minutes \\
\hline Teacher lecture related to topic. & Teacher lecture related to topic. \\
\hline $\begin{array}{l}\text { The lessons in the subsequent sessions } \\
\text { will adhere to this format. }\end{array}$ & $\begin{array}{l}\text { The lessons in the subsequent sessions will } \\
\text { adhere to this format. }\end{array}$ \\
\hline
\end{tabular}




\section{Appendix $J$}

Instruments, Treatment and Comparison Groups

Treatment Group AAAS Physical Science comprehensive pretest

AAAS Physical Science comprehensive pretest

CELLA

Eighth-grade $F S A$ ELA reading

Eighth-grade FCAT 2.0 Science
Comparison Group

AAAS Physical Science comprehensive pretest

AAAS Physical Science comprehensive pretest

CELLA

Eighth-grade $F S A E L A$ reading

Eighth-grade FCAT 2.0 Science 


\section{Appendix $K$}

Results of Testing Research Hypotheses

Each hypothesis was evaluated through the utilization of quantitative data analysis. Following is a presentation of the results.

Results of Testing Research Hypothesis One

After treatment, an analysis of covariance showed no significant difference between the mean scores of the treatment and comparison groups indicting a lack of effect on reading achievement. Means (with standard deviations in parenthesis) for the treatment and comparison groups were 21.21 (6.578) and 23.44 (9.581), respectively, with a $95 \%$ CI $[20.831,23.729], F(1,72)<.001, p=.994$.

Results of Testing Research Hypothesis Two

After treatment, a factorial analysis of covariance showed no significant interaction between treatment and prior science knowledge. This indicated a lack of effect on reading achievement regardless of background knowledge in science. There was no main effect for treatment, $F(2,40)=.042, p=.838$. There was no main effect for FCAT 2.0 Science group, $F(2,40)=.087, p=.917$. There was no main effect for study group membership, FCAT 2.0 Science group, and posttest scores, $F(2,40)=$ $.042, p=.959$. 
The mean (with the standard deviation in parenthesis) for the treatment group was 20.727 (1.757) with a 95\% CI [17.175, 24.278]. The mean for the comparison group was $21.212(1.528)$ with a $95 \%$ CI [18.123, 24.301].

Means (with standard deviations in parenthesis) for the treatment group for FCAT 2.0 Science levels were as follows: for Level 1 (the lowest achievement level), 20.847 (20.39) with a 95\% CI [16.727, 24.967]; for Level 2 (the moderate achievement level), 21.449 (1.596) with a 95\% CI [18.224, 24.674]; and for Level 3 (the high achievement level), 19.885 (4.565) with a 95\% CI [10.658, 29.111].

Means (with standard deviations in parenthesis) for the comparison group for FCAT 2.0 Science levels were as follows: for Level 1 (the lowest achievement level), 20.555 (2.855) with a 95\% CI [14.785, 26.325]; for Level 2 (the moderate achievement level), 21.600 (2.124), with a 95\% CI [17.307, 25.893]; and for Level 3 (the high achievement level), 21.480 (2.926) with a 95\% CI [15.567, 27.393].

Results of Testing Research Hypothesis Three

Students were divided into two subgroups comprised of those scoring equal to or above the median score on the Florida Standards Assessment English Language Arts and those scoring below the median score.

After treatment, a factorial analysis of covariance showed no significant interaction between treatment and reading level. This indicated a lack of effect on reading achievement regardless reading level. There was no main effect for treatment, $F(1,43)=$ 2.656, $p=.110$. There was no main effect for FSA group, $F(1,43)=.149, p=.701$. 
There was no main effect for study group membership, FSA group, and posttest scores, $F$ $(1,43)=.678, p=.415$.

The mean (with the standard deviation in parenthesis) for the treatment group was 21.768 (1.129) with a 95\% CI [19.491, 24.044]. The mean for the comparison group was $24.746(1.422)$ with a $95 \%$ CI $[21.879,27.612]$.

Means (with standard deviations in parenthesis) for the treatment group for FSA reading levels were as follows: for the lower achievement FSA group, 22.124 (1.765) with a 95\% CI [18.564, 25.684]; for the higher achievement FSA group, 21.411 (1.509) with a $95 \%$ CI $[18.369,24.454]$.

Means (with standard deviations in parenthesis) for the comparison group for FSA reading levels were as follows: for the lower achievement FSA group, 23.618 (2.274) with a 95\% CI [19.032, 28.205]; for the higher achievement FSA group, 25.837 (1.803) with a $95 \%$ CI [22.238, 29.508].

Results of Testing Research Hypothesis Four

After treatment, a factorial analysis of covariance showed no significant difference between mean posttest scores of treatment and comparison groups relative to level of English language proficiency. This indicated a lack of effect on reading achievement regarding general ESOL level.

The mean (with the standard deviation in parenthesis) for the treatment group was $20.761(1.224)$ with a $95 \%$ CI $[18.312,23.209]$. The mean for the comparison group was 20.911 (1.132) with a 95\% CI [18.647, 23.176]. 
Means (with standard deviations in parenthesis) for the treatment group for ESOL levels were as follows: for the lower English proficiency group, 19.766 (2.184) with a 95\% CI [15.397, 24.134]; for the higher English proficiency group, 21.756 (1.114) with a 95\% CI [19.528, 23.984].

Means (with standard deviations in parenthesis) for the comparison group for ESOL levels were as follows: for the lower English proficiency group, 16.586 (1.786) with a 95\% CI [13.013, 20.159]; for the higher English proficiency group, 25.237 (1.441) with a $95 \%$ CI $[22.354,28.119]$.

Univariate analysis of variance showed a significant difference, 8.651 points, between the mean scores of high and low ESOL level comparison group students. Whereas, there was no significant difference, 1.990 points, between the mean scores of high and low ESOL level treatment group students. The lower English language proficiency treatment group students performed closer to the performance level of the higher English language proficiency treatment group students. This appears to indicate that the treatment had a positive impact on low ESOL level participants.

Results of Testing Research Hypothesis Five

After treatment, a factorial analysis of covariance showed no significant interaction between treatment and gender. There was no main effect. This indicated a lack of effect on reading achievement regardless gender.

There was no main effect for treatment, $F(1,72)=.016, p=.900$. There was no main effect for gender, $F(1,72)=2.543, p=.115$. There was no main effect for study group membership, gender, and posttest scores, $F(1,72)=2.775, p=.100$. 
Means (with standard deviations in parenthesis) for the treatment group for gender were as follows: for boys, 22.214 (1.316) with a 95\% CI [19.590, 24.838]; for girls, 22.126 (1.562) with a 95\% CI [19.012, 25.241].

Means (with standard deviations in parenthesis) for the comparison group for gender were as follows: for boys, 24.434 (1.424) with a 95\% CI [21.595, 27.273]; for girls, 19.535 (1.609) with a 95\% CI [16.327, 22.744]. 


\section{Appendix L}

Data Related to Observation of Final Summarization and Discussion Session of Treatment Groups by Researcher

Teacher 1

[1] Teacher conforms to script: Compliance was acceptable.

[2] Teacher redirects students: There were no instances requiring redirection.

[3] Teacher refrains from participation in student discussion groups: The instructor did not interfere with student interaction.

[4] Discipline incidents: The teacher reported that one student had a record of disruptive classroom behavior and noncompliance regarding academic activities. He was isolated from the small groups prior to commencement of activities.

[5] Other factors: No other significant factors occurred.

Teacher 2

[1] Teacher conforms to script: Compliance was acceptable.

[2] Teacher redirects students: There were no instances requiring redirection.

[3] Teacher refrains from participation in student discussion groups: The instructor did not interfere with student interaction.

[4] Discipline incidents: There were no discipline problems.

[5] Other factors: No other significant factors occurred. 


\section{Appendix $M$}

Teachers' Interview Responses:

Educational Background, Training, Experience and Perceptions of Intervention

Teacher 1

Part I

[1] How long have you been a classroom teacher?

Twenty-two years.

[2] How long have you taught general education MDCPS science classes?

Seventeen years. I switched over after the first five years. [I had] taught ESE [special education] students for five years.

[3] What grades have you taught?

I taught grades 6 through 8 in middle school and in high school, I have taught tenth, eleventh, and twelfth grade. And now I teach ninth grade physical science.

[4] Were you trained as a secondary school science teacher?

No. I added the teaching part on to my extensive science background. I went back and completed a master's degree in varying exceptionalities when I became interested in special education.

[5] In what area is your bachelor's degree?

Biology.

[6] Do you have an advanced degree?

Yes. I have a master's degree.

[7] Did you complete a teacher internship?

No. 


\section{Part II}

[1] What do you feel went well?

I saw some of the students focus and tried [sic] to do a good job.

[2] What do you feel did not go well?

I think the time constraints were an impediment to some of the students, considering I have so many low level and ESOL [English for Speakers of Other Languages] students.

[3] Can you suggest a means by which the intervention could be improved?

Yes. I believe that beginning the intervention at the beginning of the school year, August, instead of later would benefit the students and maybe improve their reading comprehension and success on exams throughout the year.

Teacher 2

Part I

[1] How long have you been a classroom teacher?

Twenty-one years.

[2] How long have you taught general education MDCPS science classes?

Thirteen years.

[3] What grades have you taught?

Second, third, fourth, fifth, eighth, ninth, eleventh, twelfth.

[4] Were you trained as a secondary school science teacher? Internship [in science education]? No.

[5] In what area is your bachelor's degree? 
Elementary [education].

[6] Do you have an advanced degree?

Yes. Masters's of science [in] science education

[7] Did you complete a teacher internship?

Yes. Elementary. Fourth grade.

Part II

[1] What do you feel went well?

The sentence starters [academic conversation discourse moves] helped students when summarizing on their own.

[2] What do you feel did not go well?

Students needed more time with group discussion.

[3] Can you suggest a means by which the intervention could be improved?

This intervention would improve if used in a smaller setting with adults who could coach and model the process. 
VITA

\title{
EDWARD CHARLES BURKE
}

\author{
Born, Jersey City, New Jersey
}

1982

American Montessori Society Teaching Training

Malcolm X - Martin Luther King College

New York, New York

1987

B. S., Business

University of the State of New York

Albany, New York

2005

M. S., Varying Exceptionalities Special Education

Nova Southeastern University

Fort Lauderdale, Florida

1982-1984

Classroom Teacher

Nazareth Montessori School

New York, New York

1984-1986

Classroom Teacher

E.F.C. Montessori School

Satellite Beach, Florida

1988-present

Classroom Teacher

Miami-Dade County Public Schools

Miami, Florida

\section{PRESENTATIONS}

Burke, E. C. (2009, December). Training graduate students in reading education in the presentation of children's literature. Presented at the annual meeting of the American Reading Forum, Sanibel Island, FL.

Burke, E. C. (2010, December). Meaning negotiated through independently-written summaries and oral academic conversations, enhancing comprehension of science text by ninth-grade, English learners: Pilot study. Presented at the annual meeting of the American Reading Forum, Sanibel Island, FL. 
Burke, E. C. (2012, December). Meaning negotiated through independently-written summaries and oral academic conversations, enhancing comprehension of science text by ninth-grade, English learners: A qualitative investigation. Presented at the annual meeting of the American Reading Forum, Sanibel Island, FL. 